\title{
Coordinated Plasticity of Synapses and Astrocytes Underlies Practice-Driven Functional Vicariation in Peri-Infarct Motor Cortex
}

\author{
(DSoo Young Kim, ${ }^{1 *}$ J. Edward Hsu, ${ }^{2,3 *}$ Lincoln C. Husbands, ${ }^{4}$ Jeffrey A. Kleim, ${ }^{5}$ and Theresa A. Jones ${ }^{3,4}$ \\ ${ }^{1}$ Department of Integrative Biology, University of California, Berkeley, California 94720, ${ }^{2}$ Department of Neurosurgery, McGovern Medical School, \\ University of Texas Health Science Center, Houston, Texas 77030, ${ }^{3}$ Institute for Neuroscience, ${ }^{4}$ Psychology Department, University of Texas, Austin, Texas \\ 78712, and ${ }^{5}$ School of Biological and Health Systems Engineering, Arizona State University, Tempe, Arizona 85287
}

\begin{abstract}
Motor rehabilitative training after stroke can improve motor function and promote topographical reorganization of remaining motor cortical movement representations, but this reorganization follows behavioral improvements. A more detailed understanding of the neural bases of rehabilitation efficacy is needed to inform therapeutic efforts to improve it. Using a rat model of upper extremity impairments after ischemic stroke, we examined effects of motor rehabilitative training at the ultrastructural level in peri-infarct motor cortex. Extensive training in a skilled reaching task promoted improved performance and recovery of more normal movements. This was linked with greater axodendritic synapse density and ultrastructural characteristics of enhanced synaptic efficacy that were coordinated with changes in perisynaptic astrocytic processes in the border region between head and forelimb areas of peri-infarct motor cortex. Disrupting synapses and motor maps by infusions of anisomycin (ANI) into anatomically reorganized motor, but not posterior parietal, cortex eliminated behavioral gains from rehabilitative training. In contrast, ANI infusion in the equivalent cortical region of intact animals had no effect on reaching skills. These results suggest that rehabilitative training efficacy for improving manual skills is mediated by synaptic plasticity in a region of motor cortex that, before lesions, is not essential for manual skills, but becomes so as a result of the training. These findings support that experience-driven synaptic structural reorganization underlies functional vicariation in residual motor cortex after motor cortical infarcts.
\end{abstract}

Key words: anisomycin; intracortical microstimulation mapping; ischemic stroke; skilled reaching; transmission electron microscopy

Significance Statement

Stroke is a leading cause of long-term disability. Motor rehabilitation, the main treatment for physical disability, is of variable efficacy. A better understanding of neural mechanisms underlying effective motor rehabilitation would inform strategies for improving it. Here, we reveal synaptic underpinnings of effective motor rehabilitation. Rehabilitative training improved manual skill in the paretic forelimb and induced the formation of special synapse subtypes in coordination with structural changes in astrocytes, a glial cell that influences neural communication. These changes were found in a region that is nonessential for manual skill in intact animals, but came to mediate this skill due to training after stroke. Therefore, motor rehabilitation efficacy depends on synaptic changes that enable remaining brain regions to assume new functions.

\section{Introduction}

Sufficient brain damage in adulthood usually results in enduring behavioral impairment, presumably due to localization of function in the mature nervous system. The partial return of func-

Received May 11, 2017; revised Oct. 5, 2017; accepted Nov. 3, 2017.

Author contributions:S.Y.K., J.E.H., J.A.K., and T.A.J. designed research;S.Y.K., J.E.H., L.C.H., and T.A.J. performed research; J.A.K. contributed unpublished reagents/analytic tools; S.Y.K., J.E.H., and T.A.J. analyzed data; S.Y.K. and T.A.J. wrote the paper.

This work was supported by the National Institutes of Health (Grant NS056839 to T.A.J).

The authors declare no competing financial interests.

*S.Y.K. and J.E.H. contributed equally to this work. tional ability that occurs spontaneously has been attributed to resolution of diaschisis and other transient events, the reorganization of neural circuitry in brain regions connected to the injury (Feeney and Baron, 1986; Carrera and Tononi, 2014; Jones and Adkins, 2015; Cho et al., 2016), and the use of altered behavioral strategies to compensate for lost function (Whishaw et al., 1991;

Correspondence should be addressed to Soo Young Kim, Center for Synaptic Brain Dysfunctions, Institute for Basic Science and Department of Biological Sciences, Korea Advanced Institute of Science and Technology, 291 Daehak-ro, Yuseong-gu, Daejeon 34141, Korea. E-mail: sooykim29@gmail.com.

DOI:10.1523/JNEUROSCI.1295-17.2017

Copyright $\odot 2018$ the authors $\quad 0270-6474 / 18 / 380093-15 \$ 15.00 / 0$ 
Braun et al., 2012; Allred et al., 2014). Although it is often far from sufficient to fully restore function, further improvements can be driven by rehabilitation approaches (Veerbeek et al., 2014).

Chronic disability in the use of one hand is particularly prevalent after stroke (Lawrence et al., 2001). Poststroke motor rehabilitative training can improve manual skills and reorganize movement representations ("motor maps") to increase the topographical territory of hand movements in remaining motor cortex (Nudo and Milliken, 1996; Liepert et al., 2000; Sawaki et al., 2008; Tennant et al., 2015). The reorganized cortex is important for functional improvements. In rats with motor cortical infarcts, ablation of the reorganized cortex after a period of rehabilitative training in a skilled reaching task reinstates functional deficits (Castro-Alamancos and Borrel, 1995; Conner et al., 2005) and pharmacological disruption of motor cortical plasticity hinders training-induced functional improvement (Conner et al., 2005; Schubring-Giese et al., 2016; Wang et al., 2016). However, cortical map reorganization seems to reflect other mechanisms of rehabilitative training efficacy because map changes follow the behavioral improvements (Nishibe et al., 2015).

There are numerous changes in peri-infarct cortex that may contribute to functional improvement after stroke (Carmichael, 2012; Zeiler and Krakauer, 2013; Starkey and Schwab, 2014). Ischemic damage to cortex upregulates plasticity-related proteins in peri-infarct cortex (Kleim et al., 2003a; Carmichael, 2006) and instigates sprouting of corticocortical (Dancause et al., 2005; Clarkson et al., 2013) and corticofugal (Carmichael, 2003; Starkey et al., 2012) projections. Dendrites and spines proximal to an infarct are lost rapidly, followed by increased formation of new spines that returns spine density to normal levels over time (Brown et al., 2007; Brown et al., 2008) despite persistent loss of dendrites (Mostany and Portera-Cailliau, 2011). It is likely that rehabilitative training can interact with such postischemic reactions to promote functionally adaptive neural changes because many aspects of lesion-induced plasticity can be shaped by behavioral manipulations (Johansson, 2000; Murphy and Corbett, 2009; Jones and Adkins, 2015; Jones, 2017). Rehabilitative training after lesions of primary motor cortex promotes dendritic growth and spine addition in contralesional (Biernaskie and Corbett, 2001) and pre/supplementary motor cortex (Wang et al., 2016) and increases the expression of synapse-related proteins in peri-infarct cortex (Pagnussat et al., 2012). Although a better understanding of synaptic substrates of motor rehabilitative training could support precise therapeutic targets for enhancing its efficacy, a detailed examination of its influence on synapse-level structural changes in peri-infarct motor cortex has been lacking.

In the present study, we characterized the ultrastructural-level responses of synapses and astrocytes in peri-infarct cortex to motor rehabilitative training. The region of focus, the anterior border area between the caudal forelimb area (CFA) of primary motor cortex and surrounding head representations, was chosen because rehabilitative reach training promotes greater forelimb representation area near this anterior border, which otherwise becomes dominated by head representations after CFA infarcts (Kim et al., 2015). We then used pharmacological disruption of this border region to test its behavioral relevance, comparing the consequences for training-induced gains in motor skill after infarcts with the maintenance of established motor skills in intact animals. We found that postinfarct rehabilitative training results in coordinated plasticity of synapses and astrocytes in a region that was not essential for the skills in intact animals. Our results suggest that functional vicariation involving specific forms of ultrastructural synaptic plasticity in the peri-infarct motor cortex underlies rehabilitation efficacy.

\section{Materials and Methods}

\section{Subjects}

A total of 84 adult (3-4 months old) male Long-Evans hooded rats were used. Rats were housed in pairs on a 12:12 h light:dark cycle and received water ad libitum. Rats used for behavioral testing were placed on scheduled feeding ( $15 \mathrm{~g}$, once per day) to avoid satiety at the time of testing. All animal use was in accordance with a protocol approved by the Animal Care and Use Committee of the University of Texas at Austin.

\section{Ischemia induction}

Rats received subtotal ischemic lesions of the CFA of primary motor cortex or sham operations in the hemisphere opposite to the preferred (for reaching) forelimb $1-2 \mathrm{~d}$ after the end of preoperative training. This infarct locus was chosen because it results in long-lasting upper limb motor impairments that resemble those of clinical stroke populations (Jones, 2017). Ischemia induction was by topical administration of endothelin-1 (ET-1) as described previously (Fuxe et al., 1997; Adkins et al., 2004; Adkins et al., 2008; Kim and Jones, 2013). Rats were anesthetized with ketamine $(90 \mathrm{mg} / \mathrm{kg})$ and xylazine $(9 \mathrm{mg} / \mathrm{kg})$, skull and dura were removed between $1.5 \mathrm{~mm}$ posterior to $2.5 \mathrm{~mm}$ anterior to bregma, and $3.0-4.5 \mathrm{~mm}$ lateral to midline, and $2.5 \mu \mathrm{l}$ of ET-1 ( $80 \mu \mathrm{M}, 0.2 \mu \mathrm{g} / \mu \mathrm{l}$ in sterile saline) was applied onto the pial surface. ET-1 was applied in 2 drops ( 1.5 and $1.0 \mu \mathrm{l}$ each) that were 2 min apart and the surgical site was left undisturbed for $10 \mathrm{~min}$ after the last drop. Gelfoam was then placed on the cortex to fill the craniectomy. Sham-operated rats received all procedures up to, but not including, skull removal to avoid the production of behavioral and neurochemical asymmetries associated with craniectomies (Adams et al., 1994).

\section{Cannula implantation}

Chronic cannulae were implanted in a subset of rats to permit cortical infusions of anisomycin (ANI) or vehicle (VEH). Rats were anesthetized with a mixture of ketamine $(90 \mathrm{mg} / \mathrm{kg}$ ) and xylazine $(9 \mathrm{mg} / \mathrm{kg})$. Guide cannulae (457 $\mu \mathrm{m}$ diameter; Plastics One) were implanted at a depth of $700 \mu \mathrm{m}$ in the CFA core $(1 \mathrm{~mm}$ anterior, $3 \mathrm{~mm}$ lateral, relative to bregma), the anteromedial CFA region bordered by head representations ("Border," $1.4 \mathrm{~mm}$ anterior, $1.5 \mathrm{~mm}$ lateral), or parietal cortex $(6 \mathrm{~mm}$ posterior, $3 \mathrm{~mm}$ lateral). Burr holes and cannulae were then covered with UV curing dental cement and guide cannulae were covered with dummy caps. Cannula implantations were done in the same surgery as the lesions or, in intact animals, after they were trained to plateau on the reaching task.

\section{Reach training and testing}

The single-pellet retrieval task was performed as described previously (Adkins et al., 2008; Kim et al., 2015). Briefly, the apparatus consists of a Plexiglas chamber with a window and an exterior shelf with wells $1 \mathrm{~cm}$ from the window to contain $45 \mathrm{mg}$ banana-flavored food pellets (Bioserve). An elevated lip at the window edge prevents pellets from being scraped into the chamber and the position of an inner chamber wall enforces the use of the trained limb for reaching. The use of the tongue was discouraged from the onset of shaping procedures by removal of the pellet if it was extended through the window. For each trial, a single pellet was placed in a well and rats were allowed up to five reach attempts. Successful reaches were defined as the animal grasping the food pellet with its forepaw, bringing it directly to its mouth, and eating it. Unsuccessful reach attempts were those in which the pellet was missed, knocked from the well, or dropped before eating. The percentage of successful reaches per reach attempt was analyzed. Before lesion or sham operations, rats were trained for 30 trials per day with the limb they preferred to reach with, as determined during a preceding shaping period, until they reached a criterion of making at least $50 \%$ successful reach attempts with this limb (6-10 d, not including the shaping period). This criterion was chosen because it approximates near-asymptotic performance levels, as established in previous studies (Luke et al., 2004; Hsu and Jones, 2005, 2006; O'Bryant et al., 2011; O'Bryant et al., 2016). Note that comparisons between two sham-operated groups (those with vs without postoperative reach training) represent the effect of practicing well established skills on anatomical/behavioral measures. Postoperative probe sessions on the reaching task consisted of 10 trials (to minimize training effects). Probe 
sessions were performed $4 \mathrm{~d}$ after the lesion (probe 1 ) and thereafter once per week (probes 2-5) in all groups. Beginning on postoperative day 5 , rehabilitative training groups received 5 consecutive days per week of training on the reaching task consisting of 60 trials or $20 \mathrm{~min}$, whichever came first, for 3-4 weeks. Weekly probe sessions occurred the day after the fifth rehabilitative training session of the week.

Abnormal reaching movements were quantified using an adaptation of the Whishaw rating scale (Whishaw et al., 1993; Metz and Whishaw, 2000) as described previously (Adkins et al., 2008; O'Bryant et al., 2016). Before surgeries and rehabilitative (Probe 1 in Fig. 1) and postrehabilitative (Probe 5 in Fig. 1) training, frame-by-frame playback of five successful trials per day was used to observe seven sequential movement components: aim, advance, digits open, grasp, supination 1 , supination 2 , and release (of the pellet into the mouth). Movements were considered abnormal if they were absent (compensated for entirely by other body movements), unrecognizable, or recognizable but slightly abnormal. The rater was blinded to experimental condition. Consistent with previous findings (Adkins et al., 2008; O'Bryant et al., 2016), the last four subcomponents (grasp through release) were affected the most consistently by the lesions. Data were analyzed as the ratio of abnormal grasp through release movements/total trials.

\section{Behavioral testing after ANI infusions}

Animals were briefly sedated with isoflurane $(<2 \mathrm{~min})$ and $1.0 \mu$ l of ANI (50 or $100 \mu \mathrm{g} / \mu \mathrm{l}$ in ACSF) or VEH (ACSF only) was infused at a rate of $0.5 \mu \mathrm{l} / \mathrm{min}$ into cortex (1200 $\mu \mathrm{m}$ depth). Similar volumes and concentrations of ANI infusions have been found to have highly localized effects (Wanisch and Wotjak, 2008; Sharma et al., 2012). The cannula was left in place for $2 \mathrm{~min}$ to allow for diffusion. No gross impairments in the forelimb contralateral to the injection, such as failure to support body weight or to perform reaching movements, were found after ANI infusions. All postinfusion probe sessions on the reaching task consisted of 30 trials.

Intact animals were used to compare the effects of ANI infusions in the CFA core $(n=7)$ versus border $(n=6)$ on performance of an established reaching skill. After training to proficiency on the single-pellet retrieval task and implantation of guide cannula over CFA, reaching performance was tested on 2 consecutive days to probe for any residual implantation effects. Thereafter, each animal received infusions of VEH followed by $50 \mu \mathrm{g} / \mu \mathrm{l} \mathrm{ANI}$ and then $100 \mu \mathrm{g} / \mu \mathrm{l}$ ANI, with 2-3 d between each infusion. After each infusion, animals were tested $2 \mathrm{~h}$ and again $24 \mathrm{~h}$ later on the reaching task. An additional test was performed $48 \mathrm{~h}$ after the second ANI infusion.

A separate study tested the effects of ANI infusions in the perilesion cortex on Post-RT performance. After 3 weeks of rehabilitative training and probe testing, animals received VEH infusions into either the CFA border or posterior parietal cortex, followed by reaching probe sessions immediately and $24 \mathrm{~h}$ later (post-VEH probes). There was no significant difference in reaching performance between the two tests within subjects, and data were therefore combined for statistical analysis. One day after the second post-VEH probe, animals received either ANI $(n=8)$ or VEH $(n=6)$ infusions in the border or ANI infusions in parietal cortex $(n=$ 6) and were tested $2 \mathrm{~h}$ later (post-ANI probe). A small set of norehabilitative training controls (No-RT; $n=4$ ) was included to verify the effects of rehabilitative training and this group received CFA border infusions of ANI.

\section{Assessment of ANI effects on forelimb motor maps}

Intracortical microstimulation (ICMS) mapping was used to compare the effects of ANI infusions in the CFA core versus border on forelimb motor maps of intact animals. Standard ICMS was performed as described previously (Tennant et al., 2011; Kim et al., 2015). Briefly, naive rats $(n=13)$ were anesthetized with ketamine $(100 \mathrm{mg} / \mathrm{kg})$ and xylazine $(8 \mathrm{mg} / \mathrm{kg})$ followed by supplemental ketamine (10 $\mathrm{mg}$ per injection) to maintain a superficial anesthetic plane. Bilateral craniectomies were made, cisterna magna was punctured (to prevent cortical upwelling), and warm silicone oil $\left(37^{\circ} \mathrm{C}\right)$ was applied to exposed cortex. A digital image of the exposed cortical surfaces was overlaid with a grid $(470 \times 470 \mu \mathrm{m}$ increments) and a glass microelectrode (filled with $3 \mathrm{M} \mathrm{NaCl}$ and platinum wire) was lowered to a depth of $1550 \mu \mathrm{m}$ at the grid intersections in systematic order to delineate the CFA. The rostral forelimb area (RFA, analogous to pre/supplementary motor cortex) was also delineated in a subset of animals. At each site, $1 \mathrm{~Hz}$ pulse trains consisting of $13200 \mu \mathrm{s}$ monophasic cathodal pulses were delivered at a rate of $350 \mathrm{~Hz}$ while gradually increasing amplitude until a visible movement was observed. The site was considered nonresponsive if no movement was observed at $\leq 60 \mu \mathrm{A}$. Jaw, neck, vibrissae, trunk, and hindlimb movements were also observed to define CFA and RFA borders. Forelimb movements were classified as distal (wrist and digits) and proximal (elbow and shoulder).

Remapping was performed $30 \mathrm{~min}$ after infusions of either $1 \mu \mathrm{l}$ of ANI $(100 \mu \mathrm{g} / \mu \mathrm{l})$ or VEH (ACSF) into the CFA core or border using the same coordinates as the cannulae implantations above with minor adjustments as needed to avoid penetrating surface vasculature. Infusions were made over $1 \mathrm{~min}$ via glass micropipette in layer $\mathrm{V}$ and the pipette was then left undisturbed for $2 \mathrm{~min}$. All responsive sites in the baseline map were then retested. Most animals $(n=8)$ received infusions into the CFA core of ANI in one hemisphere and VEH in the other, in counterbalanced order. A subset $(n=6)$ of these animals were transcardially perfused immediately after the last map and processed for TEM analysis for within-animal comparisons of ANI versus VEH effects on synaptic densities in motor cortex. In one of these animals, in the same hemisphere in which VEH was infused in the core, ANI was infused at the border followed by a third remapping. There were no effects that could be attributed to infusion condition order. The remaining animals received unilateral remapping after infusions of ANI in the border $(n=5)$, ANI in the core $(n=1)$, or VEH in the core $(n=1)$. One border infusion was mistakenly given too caudally (at approximately bregma), but the postinfusion forelimb movement representation area was within the range of the other postborder infusion maps. The experimenter performing ICMS was blinded to the drug condition. Some of the baseline map data were used in another study (Kim et al., 2015).

\section{Histological methods}

Animals were anesthetized with a lethal dose of sodium pentobarbital and perfused intracardially with $0.1 \mathrm{~m}$ phosphate buffer followed by fixative in the same buffer $1 \mathrm{~d}$ after the final probe session of the behavioral experiments and after the final map in the ICMS experiments. For TEM analyses, the perfusion fixative was $2 \%$ paraformaldehyde and $2.5 \%$ glutaraldehyde. Within $24 \mathrm{~h}$ of perfusion, alternating sets of 200-, 100-, and two $50-\mu \mathrm{m}$-thick sections of the cerebrum were cut using a Leica VT1000S vibratome. The $50 \mu \mathrm{m}$ sections were stained with Toluidine blue for lesion reconstruction and volume measurement. The lateral agranular cortex $(\mathrm{AGl})$ medial to the lesions and near the border of the medial agranular cortex (AGm) between 1.2 and $1.6 \mathrm{~mm}$ anterior to bregma was dissected out as described previously (Adkins et al., 2008). This cytoarchitecturally defined sample site corresponds to the medial border region between CFA and the head representation area of sensorimotor cortex (Neafsey et al., 1986; Tennant et al., 2011; Smith and Alloway, 2013). Samples were placed in cacodylate-buffered osmium tetroxide, en bloc stained with $2 \%$ uranyl acetate for $45 \mathrm{~min}$, and dehydrated and sandwich embedded in Eponate-12 resin. Semithin sections (0.8 $\mu \mathrm{m}$ thickness) were stained with Toluidine blue and used to estimate neuronal density and localize the region for electron microscopic sampling. Neuronal density $(N v)$ was estimated using the physical disector method in semithin sections, but there were no differences due to the lesions, training conditions, or VEH/ANI injections (Table 1). Serial silver gray ultrathin $(70 \mathrm{~nm})$ sections for TEM were obtained from the osmicated samples using a Leica Ultracut R microtome, mounted onto slotted copper grids coated with formvar film, and stained with lead citrate.

\section{Lesion reconstruction and volume estimates}

Lesion extent was reconstructed onto schematic coronal sections adapted from Paxinos and Watson (1986). The volumes of remaining cortex ipsilateral and contralateral to the lesion were measured to estimate tissue loss based on interhemispheric volume difference. The sampling scheme focused on the region targeted by the lesion, starting with the appearance of the head of the caudate nucleus as the first of six sections spaced $800 \mu \mathrm{m}$ apart (brains used for TEM) or seven sections spaced 600 
Table 1. Structural features of neurons and astrocytes in layer $V$ of the peri-infarct cortex

\begin{tabular}{llll}
\hline Density of neurons & & & \\
\hline Group & $\mathrm{Nv}\left(\right.$ per $\left.\mathrm{mm}^{3}\right)$ & Group & $\mathrm{Nv}($ per mm \\
\end{tabular}

Dendritic measures

\begin{tabular}{lll}
\hline Group & $S V_{\text {den }}\left(\mu \mathrm{m}^{-1}\right)$ & $S V_{\text {den }} / V v_{\text {den }}$ \\
\hline Sham + CTL & $0.82 \pm 0.04$ & $4.57 \pm 0.17$ \\
Sham + RT & $0.80 \pm 0.03$ & $4.22 \pm 0.09$ \\
Les + CTL & $0.74 \pm 0.02$ & $4.67 \pm 0.23$ \\
Les + RT & $0.75 \pm 0.03$ & $4.56 \pm 0.15$
\end{tabular}

Various structural features of astrocytes

\begin{tabular}{llll}
\hline Group & $V_{\text {ast }}$ & $S V_{\text {ast }}\left(\mu \mathrm{m}^{-1}\right)$ & $\begin{array}{l}\text { Mean astrocytic } \\
\text { coverage per synapse }\end{array}$ \\
\hline Sham + CTL & $0.064 \pm 0.004$ & $0.940 \pm 0.048$ & $0.151 \pm 0.012$ \\
Sham + RT & $0.058 \pm 0.003$ & $0.935 \pm 0.036$ & $0.159 \pm 0.008$ \\
Les + CTL & $0.055 \pm 0.002$ & $0.905 \pm 0.056$ & $0.155 \pm 0.012$ \\
Les + RT & $0.062 \pm 0.003$ & $0.972 \pm 0.050$ & $0.166 \pm 0.015$
\end{tabular}

Data are shown as means \pm SE. The mean astrocytic coverage per synapse was estimated by the formula: $S v_{\text {apposed }} /$ $N v_{\text {syn }}$ where $S v_{\text {apposed }}$ is the surface density of astrocytic membrane apposed with synaptic elements and $N v_{\text {syn }}$ is the numerical density of synapses.

$N v$, numerical density of neuronal nuclei; $S V_{\text {den }}$, surface densities of dendrites; $V v_{\text {den }}$ volume fraction of dendrites. $V V_{\text {ast }}$, astrocytic volume fractions; $S V_{\text {ast }}$, surface densities of astrocytic membrane.

$\mu \mathrm{m}$ apart (remaining brains). The area of remaining non-necrotic/nongliotic cortex in each section was measured using Neurolucida (MBF Bioscience) perimeter tracing software. Volume was estimated as the product of the total area (summed over all sections) and the distance between section planes (Gundersen et al., 1988). Lesion volumes were calculated as the difference in cortical volume between intact and lesion hemispheres.

\section{Ultrastructural measures}

Sampling strategy. Cytoarchitectonics in adjacent $50-\mu \mathrm{m}$-thick sections and low-magnification semithin images were used to localize the sample area to layer $\mathrm{V}$ of AGl between AGm and the medial border of the lesion, excluding fibrotic and necrotic tissue between 1.2 and $1.6 \mathrm{~mm}$ anterior to bregma. We focused on layer $\mathrm{V}$ because it has been demonstrated repeatedly to undergo synaptic changes in response to skill learning and to these types of lesions (Kleim et al., 2003b; Kleim et al., 2004; Jones, 2017). Four sets of four serial adjacent TEMs spanning at least 11 sections were imaged from serial silver gray $(70 \mathrm{~nm})$ sections using a Philips 208 TEM with a Hamamatsu 1394 digital camera $(14,000 \times$ image capture magnification). The first set of four serial images was taken in the lateral extent of the sample. Moving medially, the first section of the next series was taken in the same section as the last section from series 1 and then from three additional sections. This was repeated for the next two series. This strategy minimizes the contribution of section-to-section variability in thickness. The sampling strategy was evaluated by coefficient of error (CE), calculated as follows: $\mathrm{CE}=$ coefficient of variance $/ \mathrm{V}$ number of samples per brain (West and Gundersen, 1990).

Synaptic measures. The density of axodendritic (spine and shaft) synapses were estimated using the physical disector method (Sterio, 1984), as described previously (Hsu et al., 2005, Kim et al., 2015; Adkins et al., 2008). The CEs of axodendritic synaptic density ranged from 0.025 to $0.060($ median $=0.043)$ and group means ranged from $0.041($ Les + CTL $)$ to 0.043 (Sham $+\mathrm{CTL}$ ), indicating a precise sampling scheme (Geinisman et al., 1996). Synaptic density was calculated by the following formula: $\mathrm{Nv}=\Sigma \mathrm{Q}-/ \Sigma \mathrm{v}$ (frame), where $\Sigma \mathrm{Q}-$ is the sum of synapses counted per brain and $\Sigma v$ (frame) is the sum of the sample volume (188 $\mu \mathrm{m}^{3}$ ) calculated as the product of the area of one sample frame (112 $\left.\mu \mathrm{m}^{2}\right)$, distance between section planes $(70 \mathrm{~nm})$, and the number of samples (i.e., disector pairs, $n=24$ ). Subtypes of synapses including perforated synapses and synapses formed by multisynaptic boutons (MSBs) were identified as described previously (Adkins et al., 2008; Kim et al., 2015).

Dendritic measures. Dendritic processes were identified by their orderly arrangement of microtubules, irregular contours (versus the smooth cylindrical contours of axons), the presence of mitochondria, the absence of vesicles or myelin sheaths, and the frequent presence of synapses and spines (Peters et al., 1991). To estimate volume ( $V)$ and surface area $(\mathrm{Sa})$ of dendritic processes, the software program RECONTRUCT (Fiala, 2005) was used to trace identified structures. Volume fraction ( $V v=V /$ total volume $)$ and surface density $(S v=S a /$ total volume $)$ were calculated.

Astrocytic measures. Astrocytic processes in electron micrographs were identified by their relatively transparent cytoplasm, irregular and sheetlike shape, absence of dendritic and axonal characteristics (e.g., highly ordered microtubules, synaptic vesicle clusters, and myelination) and, occasionally, the presence of intermediate filaments, as described previously (Peters et al., 1991; Kim and Jones, 2010; Kim et al., 2015). Using the software RECONTSRUCT, astrocytic membranes apposed to synaptic elements were traced and their surface densities $\left(S v_{\text {apposed }}\right)$ were estimated as described above. The synaptic elements included in this measure consisted of synaptic boutons, spines, and the interface between axon-spine and axon-dendritic shaft synapses. Presynaptic boutons were identified by the presence of synaptic vesicles and absence of myelination. Postsynaptic spines were identified by the presence of synaptic densities, frequent presence of spine apparati (e.g., see Fig. 3B), and lack of presynaptic vesicles and mitochondria. Spine necks were included in the morphology measures. The percentage of astrocytic membrane apposed to synaptic elements of total astrocytic membrane was calculated as follows: (\%) $S v_{\text {apposed }} / S v_{\text {ast }}$.

\section{Experimental design and statistical analysis}

Experimental designs are summarized in Figures $1 A ; 6 A$, and $8 A$. In the study of postlesion rehabilitative training effects, data were analyzed using planned comparisons to test the following questions of primary interest: (1) whether rats that received rehabilitative training after CFA infarcts were significantly different from rats that received no-training control procedures (Les+RT vs Les + CTL) and (2) whether either lesion group was significantly different from sham-operated controls (Les+RT vs Sham groups and Les+CTL vs Sham groups). Preliminary analyses indicated no significant effects of training alone (Sham+RT vs Sham + CTL) in all but the astrocytic measures, so lesion groups were compared with both sham groups combined in the other measures. For the astrocytic measures, each lesion group was compared with the sham subgroup that was matched in training condition (i.e., Sham + CTL vs Les + CTL and Sham + RT vs Les+RT). Behavioral data were analyzed with repeated-measures ANOVAs for the effects of group and group $X$ day interactions. Post hoc analyses were performed using $t$ tests with Bonferroni-Holm correction when warranted by significant group $\times$ day interactions. Anatomical data were analyzed using one-way ANOVAs for group. Bivariate correlations were also used to assess relationships between the synaptic and behavioral variables. The behavioral effects of ANI infusions were analyzed using ANOVA for cortical location (CFA core or border) $\times$ drug condition, treated as repeated measures. ANI effects on forelimb motor maps and synaptic density were compared with VEH using one-way ANOVAs. R software was used for statistical analysis (www.r-project.org).

\section{Results}

\section{Rehabilitative reach training improved manual skill} performance in rats after motor cortical infarcts

Without rehabilitative training, unilateral ischemic lesions of the CFA of motor cortex resulted in enduring impairments in reaching performance compared with sham-operated rats (Les + CTL vs sham groups, group $\times$ week: $F_{(5,115)}=3.58, p=0.005$; Fig. $1 B)$. Rehabilitative training, consisting of extensive practice in the same reaching task (5 times per week for 4 weeks), enhanced 
A
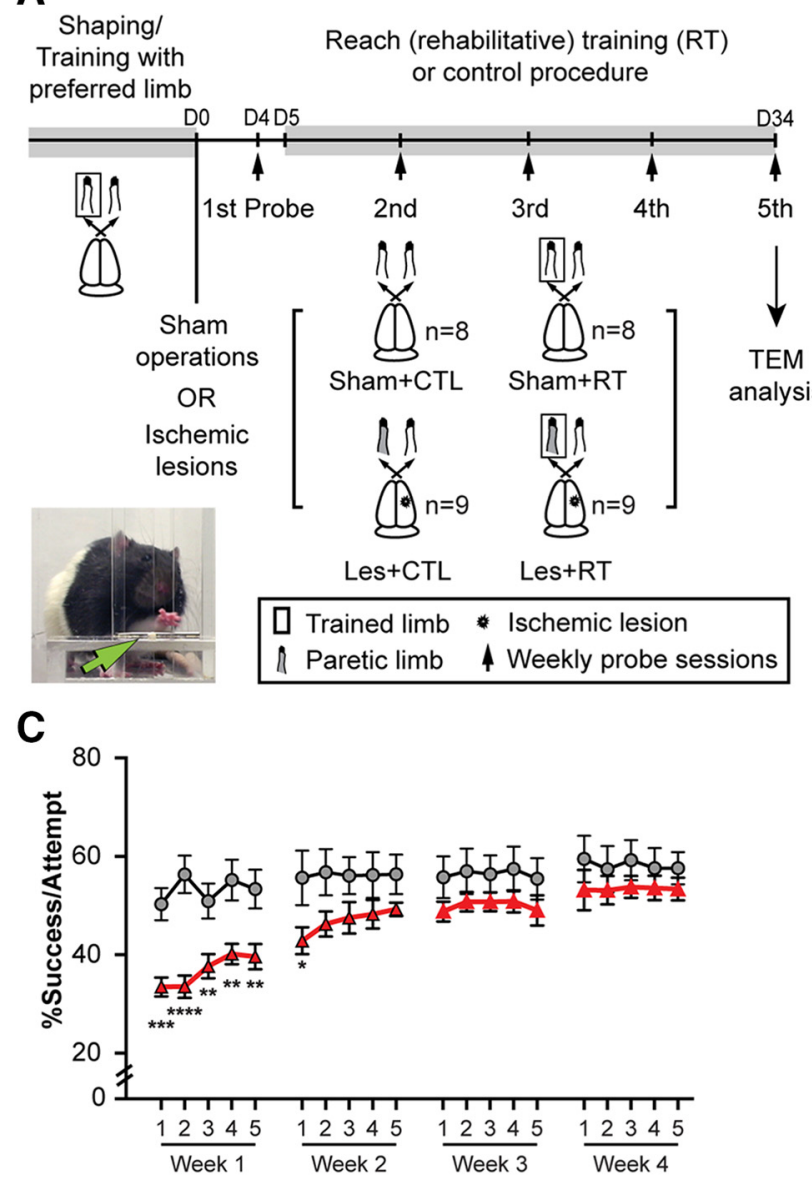

B
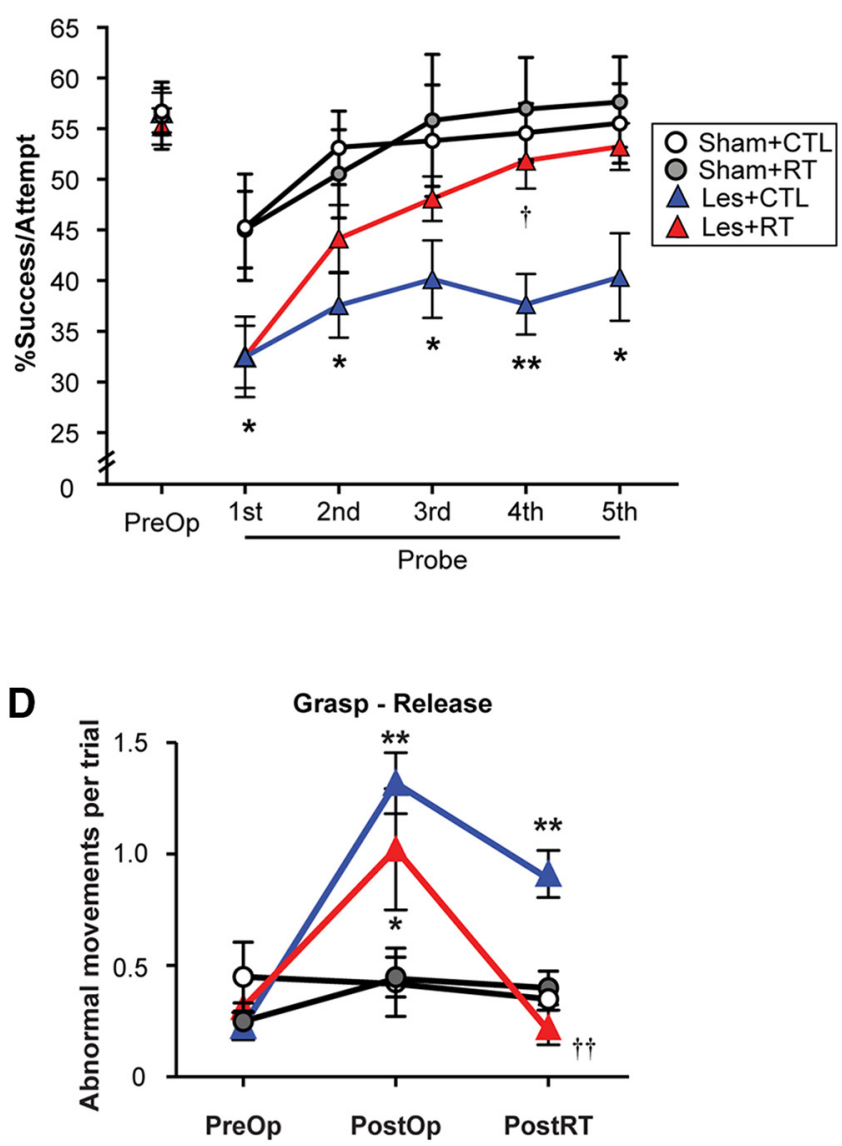

Figure 1. Skilled reaching as rehabilitation improved reaching success after unilateral ischemic lesion. $\boldsymbol{A}$, Summary of the experimental design. Rats with unilateral ischemic infarcts of the CFA of the primary motor cortex (M1) received 4 weeks of rehabilitative training in skilled reaching or control procedures. Probe trials of performance on the single-pellet retrieval task were given once a week to all rats. The photo shows a rat reaching for a food pellet (arrow) in the reaching task. $\boldsymbol{B}$, Percentage of successful retrievals on weekly probe trials of skilled reaching performance. All rats were proficient in skilled reaching before surgery. Lesions impaired reaching performance. Rehabilitative training after lesions (Les+RT) improved reaching performance on probes 4 and 5 compared with no-training controls (Les + (TL). Without rehabilitative training, postlesion impairments in reaching endured to the fifth probe compared with intact, sham-operated animals. ${ }^{*} p<$ 0.05 and ${ }^{* *} p<0.01$ in shams vs Les + CTL; $† p<0.05$ in Les + CTL vs Les + RT. C, Daily reaching performance during rehabilitative training sessions for Sham + RT and Les $+R T$ during the 4 weeks of practice. Lesion animals had gradual improvements in reaching performance over the course of rehabilitative reach training. Performance in sham-operated rats with postoperative reach training (that were practicing a previously established skill) did not change significantly over the course of the postoperative training. ${ }^{*} p<0.05,{ }^{* *} p<0.01,{ }^{* * *} p<0.001,{ }^{* * * *} p<0.0001$. $D$, Abnormalities (per trial) in grasp through release movements, which were most consistently affected by the lesions. After the rehabilitative training period, movement abnormalities persisted in the Les + CTL, but were no longer evident in Les + RT compared with shams. Postoperative (PostOP) and Post-RT data were from probes 1 and 5 , respectively. ${ }^{*} p<0.05$, ${ }^{* *} p<0.01$ versus sham; $t+p<0.001$ veresus Les + CTL.

postinfarct performance overall compared with untrained controls (Les+RT vs Les+CTL, group: $F_{(1,16)}=5.97, p=0.027$ ), an effect that increased with ongoing training (group $\times$ day: $F_{(5,80)}=$ $3.00, p=0.016)$. Note that despite the fairly small size of infarct (Fig. 2), enduring functional deficits of forelimb on the reaching task remained in the animals without rehabilitative training. Performance gains from rehabilitative training were also evident in day-to-day performance of the rehabilitative training sessions (Fig. 1C). In sham-operated rats, practice on the task did not affect postoperative performance significantly, as expected because the reaching skill was established in all animals before the surgeries. Sham-operated rats had a transient decline in reaching performance on the first probe day relative to the preoperative time point (Fig. $1 B$ ), potentially reflecting temporary effects of the surgical procedure and/or anesthesia. Consistent with this, by the following day during the rehabilitative training session, the performance of sham-operated rats, but not the lesion group, was similar to preoperative performance levels (Fig. 1C).
Motor performance improvements can reflect the restoration of normal movements or the development of alternative movement strategies that enable successful task completion despite persisting impairments. The lesions increased the frequency of abnormal forepaw grasp and wrist supination and release (hand opening) movements, consistent with previous findings (Adkins et al., 2008; O'Bryant et al., 2016). Of these, grasp and supination II, a wrist movement that orients the paw to the mouth, were most consistently affected, as evidenced by increased frequency of abnormalities in one or both movements in all Les +CTL and 8 of 9 Les+RT animals (Fig. 1D). Few of the animals showed postlesion abnormalities in pregrasp movements $(n=2$ of 9 Les+CTL, $n=2$ of 9 Les + RT, postoperative). Abnormal supination II was diminished in both lesion groups by the Post-RT time point and the pattern of recovery was not significantly different between them (Les + RT vs Les + CTL, group $\times$ day: $F_{(2,32)}=$ $1.5, p=0.24)$. In contrast, grasp abnormalities persisted in the absence of rehabilitative training, but greatly diminished as a 
A

$+1.7$

$+0.7$

FLOL

$-1.3$

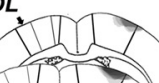

3
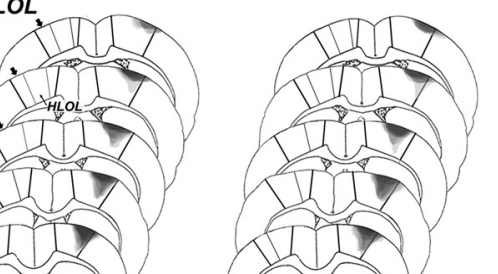

(1)

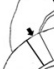

110

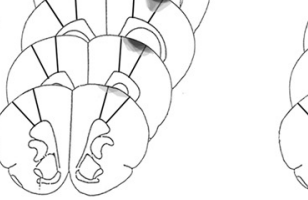

Les+CTL

B

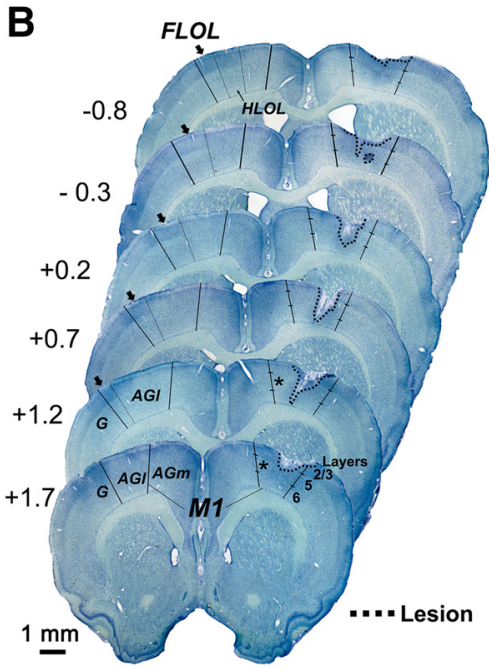

\section{C}

\section{Lesion volume}

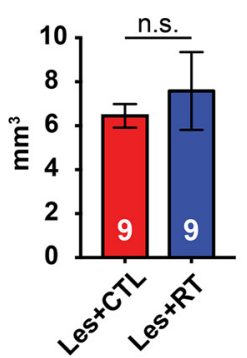

Figure 2. All lesions damaged CFA. A, Reconstructions of all lesions in Les+CTL and Les + RT groups overlaid so that the darkest areas indicate the greatest degree of lesion overlap between rats. Numbers to the left are approximate coordinates (in millimeters) relative to bregma. Lines delineate medial and lateral boundaries of $\mathrm{MI}$, inclusive of that which overlaps (OL) with primary somatosensory cortex, as found in the forelimb (FLOL) and hindlimb (HLOL) representation areas. $\boldsymbol{B}$, Representative Nissl-stained coronal sections showing lesion placement relative to cytoarchitecturally defined cortical subregions. The example is from the Les + CTL group. The CFA extends across the FLOL and adjacent lateral agranular cortex (AGI), transitioning to head representations in medial AGI and the AGm (see Materials and Methods for details). ${ }^{*}$ TEM samples were from peri-infarct AGI near its border with AGm between the coronal planes shown. $\mathbf{G}$, Granular (somatosensory) cortex. C, There was no significant difference in lesion size between groups, as estimated by the interhemispheric cortical volume difference in the sensorimotor region.

result of it (Les+RT vs Les + CTL, group $\times$ day: $F_{(2,32)}=6.66$, $p=0.004)$. By the end of rehabilitative training, movement abnormalities in the Les+RT group were no more frequent than they were preoperatively. Therefore, rehabilitative training promoted greater recovery of normal movements after the lesions. Rehabilitative training had no impact on infarct extent or size, as inferred from differences in cortical volume between the injured and contralateral hemispheres (Fig. 2).

Postinfarct rehabilitative training increased synaptic density in layer $\mathrm{V}$ of the peri-infarct CFA border in the presence of diminished dendritic quantities.

To investigate the effects of rehabilitative training on synaptic connectivity in the remaining motor cortex, we used stereological measures for TEM to quantify the density of axodendritic syn-

apses in layer $\mathrm{V}$ of motor cortex near the anteromedial border of the lesion (Fig. 3A). This location was chosen to sample from a spared portion of anterior CFA near its border with head representations because rehabilitative training promotes the maintenance of forelimb representations in the anterior CFA, but, in the absence of rehabilitative training, it becomes dominated by head representations (Kim et al., 2015). There was no difference in the density of synapses between the two sham-operated groups (Fig. $3 C$ ), which is consistent with previous findings that training in well established skills in intact animals does not have a discernable influence on either spine formation (Xu et al., 2009) or synapse number (Kleim et al., 1996). Without rehabilitative training, synaptic densities in peri-infarct cortex were similar to those of the anatomical equivalent region of sham-operated rats. In contrast, rats receiving postlesion training (Les+RT) had significantly greater overall synaptic density compared with the norehabilitative training lesion group (Les+CTL, $F_{(1,16)}=4.61, p=$ $0.048)$ and sham groups $\left(F_{(1,23)}=22.1, p<0.0001\right)$. This appeared to reflect primarily the addition of axo-spinous, rather than axo-shaft, synapses in the Les+RT group (Fig. 3D). Les+RT had significantly more axo-spinous synapses compared with sham-operated rats $\left(F_{(1,23)}=21.1, p=0.0001\right)$. There was a nonsignificant tendency for Les $+\mathrm{RT}$ to have more axo-spinous synapses compared with Les + CTL $\left(F_{(1,16)}=3.50, p=0.08\right)$. In contrast, there were no significant differences found between groups in the density of axo-shaft synapses.

The infarcts resulted in a loss of dendrites in the CFA border region, as measured by the volume fraction $(V v)$ of dendritic processes at 5 weeks postlesion compared with sham-operated rats (sham vs Les+CTL, $F_{(1,23)}=4.95, p=0.0363$; Fig. $3 E$ ). This was unaffected by postlesion rehabilitative training (Les+CTL vs Les+RT, $\left.F_{(1,16)}=0.154, p=0.701\right)$. Therefore, rehabilitative training increased synaptic density despite a persistent reduction in the volume of dendrites. In addition, the infarcts increased, relative to sham-operated rats, the numbers of synapses per unit of dendritic volume ( $23.8 \%$ increase, Les + CTL vs sham, $F_{(1,23)}=$ $7.41, p=0.012)$ and surface $\left(15.5 \%\right.$ increase, $F_{(1,23)}=5.99, p=$ 0.022; Fig. $3 F, G)$. Postinfarct rehabilitative training amplified these effects $(33.0 \%$ increase in synapse per unit dendritic volume Les+RT vs sham, $F_{(1,23)}=32.32, p<0.0001 ; 29.0 \%$ increase in synapses per unit surface of dendrites, $F_{(1,23)}=18.76, p=0.0002$; Fig. $3 F, G)$. The overall surface density and surface to volume ratio of dendrites were not significantly different due to the lesions (Table 1).

\section{Density of perforated synapses in peri-infarct cortex is strongly correlated with functional outcome}

MSBs (Fig. 4A) have been implicated in motor-training-induced synaptogenesis (Kleim et al., 2003a) and in the competitive process of a selective strengthening of synapses (Lee et al., 2013b). Perforated synapses, a subtype of synapses with discontinuous postsynaptic densities (Fig. $4 B$ ), are known to have abundant AMPA receptors as well as a larger overall postsynaptic density area, indicating a heightened level of functional efficacy and maturation (Ganeshina et al., 2004). We examined the densities of these synapse subtypes to determine their contribution to the synapse addition resulting from rehabilitative training. Rehabilitative training after lesions results in significantly increased densities of $\operatorname{MSBs}\left(F_{(1,23)}=15.89, p=0.0006\right)$ and perforated synapses $\left(F_{(1,23)}=8.04, p=0.0094\right)$ (Fig. $\left.4 C\right)$ compared with sham-operated animals. The tendency for animals with rehabilitative training to have greater densities of MSB and perforated synapses compared with those with lesions but no rehabilitative 

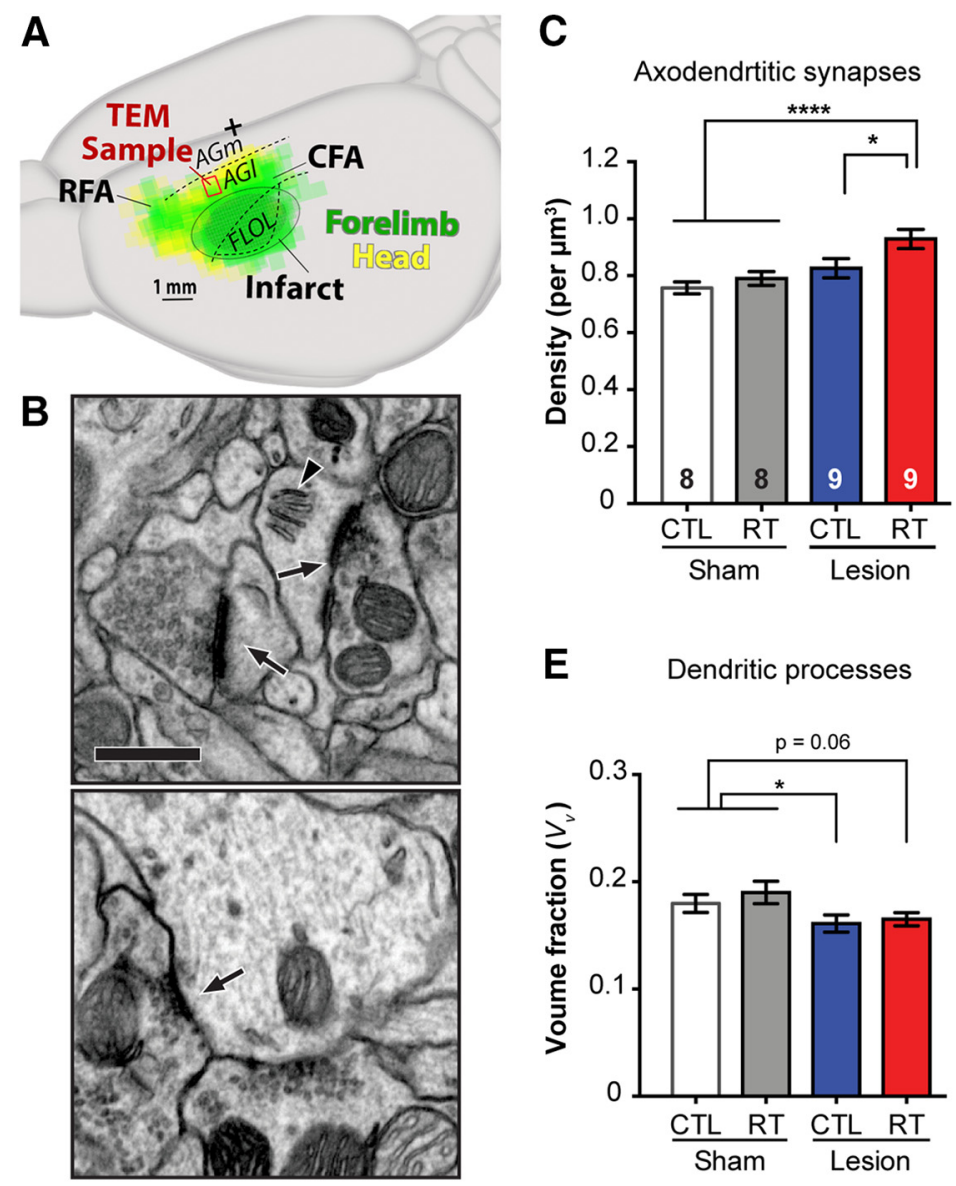

D
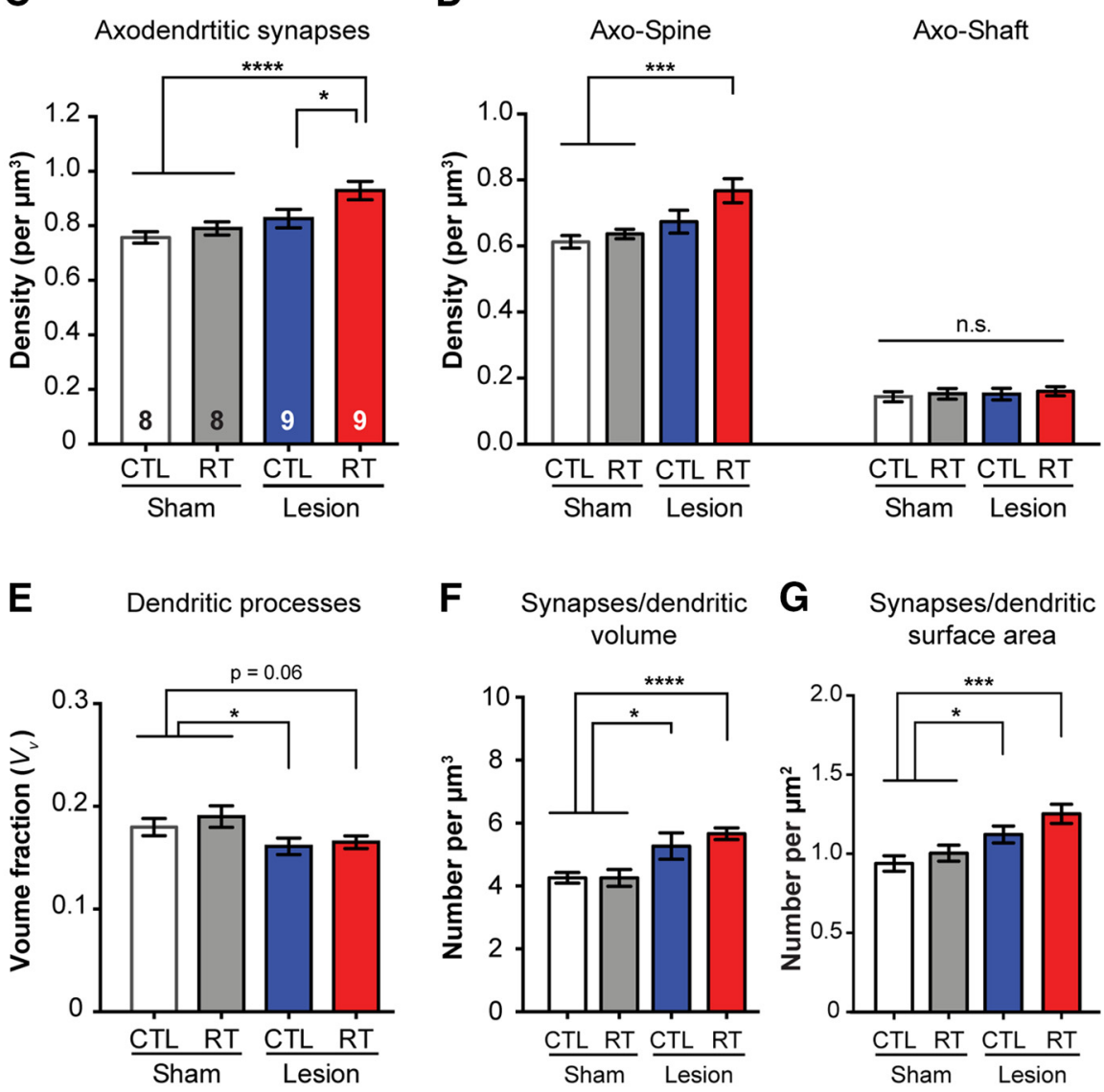

Figure 3. Rehabilitative training after CFA infarcts increased synaptic density and efficacious synapse subtypes in layer $V$ of the perilesion cortex. $A$, Illustration of infarct and TEM samples relative to forelimb and head movement representations near the border of the remaining CFA of peri-infarct cortex. The map illustration is a transparent overlay of ICMS derive maps of the CFA, RFA, and the directly adjacent head representations of naive rats (baseline maps of the ANI study described below). Dashed lines indicate the approximate locations of cytoarchitecturally defined subregions shown in Figure 2. B, Representative images of axodendritic synapses. Top, Axo-spine synapses are indicated by arrows. The spine apparatus (arrowhead) is often observed. Bottom, An axo-shaft synapse is indicated by an arrow. Scale bar, $500 \mathrm{~nm}$. C, Lesioned animals that received rehabilitative training had significantly greater synaptic density in layer $V$ of the CFA border compared with no rehabilitation and training-matched sham controls. $D$, Effect of rehabilitative training on synaptic density was evident in axo-spine synapses, whereas there was no group difference in the density of axo-shaft synapses. $\boldsymbol{E}$, Ischemic lesions decreased the volume fraction of dendrite processes in the $(F A$ border. $\boldsymbol{F}, \boldsymbol{G}$, Number of synapses per dendritic volume $(\boldsymbol{F})$ and surface area $(\boldsymbol{G})$ was increased as a result of lesions and this was amplified by rehabilitative training after the lesions. ${ }^{*} p<0.05,{ }^{* *} p<0.01,{ }^{* * *} p<0.001,{ }^{* * * *} p<0.0001$. n.s., Not significant. The numbers within the bars indicate the number of animals per group.

training failed to reach statistical significance (Les+CTL vs Les $+\mathrm{RT}, p=0.060$ and 0.081 , respectively). The percentage of MSBs and perforated synapses of all axodendritic synapses in the Les + RT group (mean \pm SE: $5.29 \pm 0.73$ and $5.32 \pm 0.68$, respectively) was significantly increased compared with sham-operated rats $($ Sham + RT: $2.79 \pm 0.68$ and $3.53 \pm 0.80$, Sham+CTL: $2.71 \pm 0.65$ and $3.62 \pm 0.39, p=0.005$ and 0.03 ) but not with Les + CTL $(3.52 \pm 0.76$ and $3.98 \pm 0.53)$. In consideration of the dendritic changes due to lesions (described above), we also analyzed quantities of these synapse subtypes per unit of dendritic volume and surface area. This analysis revealed a similar pattern as overall quantities, with the exception that MSB numbers per unit of dendritic surface area was significantly increased in lesion animals with rehabilitative training compared with lesion controls (Les +CTL vs Les +RT, $p=0.04$; Fig. $4 D, E$ ). This pattern of results is consistent with rehabilitative training interacting with and enhancing the synaptic changes that are instigated by lesions in the peri-infarct motor cortex.

As expected, the surface area of axonal boutons that formed perforated synapses was significantly greater than the overall population of synapses (mean \pm SE surface area/bouton in $\mu \mathrm{m}^{2}$ : $5.79 \pm 0.63$ vs $0.59 \pm 0.01$, perforated vs overall, respectively, $p<$
$0.0001)$. There was no significant difference between groups in either measure $(p>0.05)$. However, the density of perforated synapses in peri-infarct cortex was strongly correlated with final reaching performance (percentage success averaged over the last two probe sessions: $r=0.54, p=0.021$; Fig. $4 F$ ). Neither the overall synaptic density $(r=0.42, p=0.085)$ nor the density of MSB synapses $(r=0.32, p=0.201)$ was as strongly correlated with final reaching performance after the lesions. There were no significant relationships between quantities of these synapse subtypes and final reaching performance in sham-operated rats $(p>0.05)$.

\section{Changes in perisynaptic astrocytic processes accompanied} rehabilitative-training-induced synaptic change

Perisynaptic astrocytes tightly regulate synaptic transmission (Panatier et al., 2011). Their fine processes change dynamically, along with synaptic activity (Haber et al., 2006), and such structural association with synapses promotes excitatory synapse stability (Bernardinelli et al., 2014). Therefore, we investigated whether the lesion- and/or rehabilitative-training-induced synaptic plasticity involved changes in perisynaptic astrocytic processes. The percentage of astrocytic membrane apposed with synaptic elements (calculated as percentage surface density of astrocytic 
A

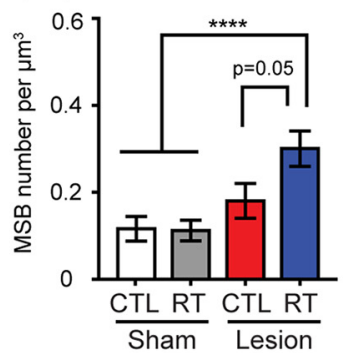

E

Synapses/Dendritic surface area

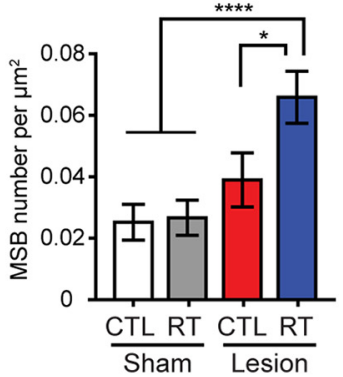

B
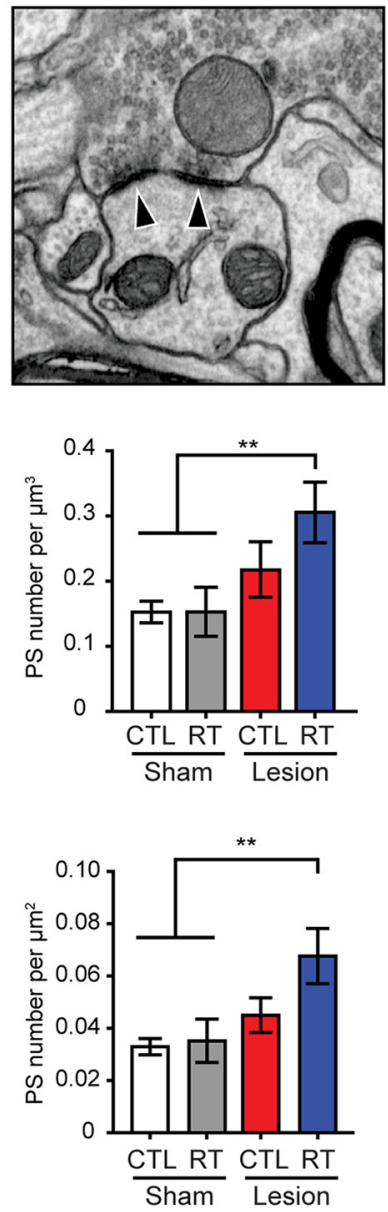

C

MSB

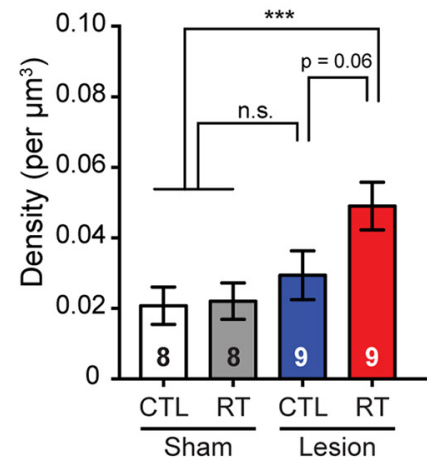

$\mathbf{F}$

Sham

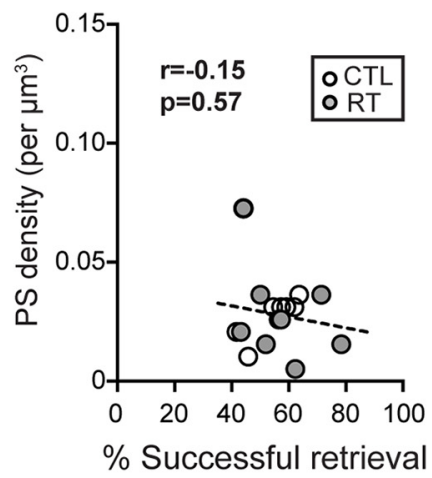

PS

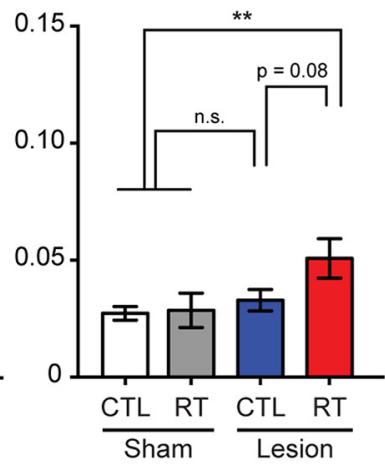

\section{Lesion}

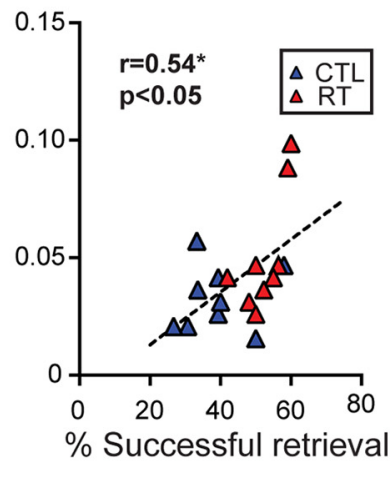

Figure 4. Increased density of perforated synapses in peri-infarct cortex was predictive of functional outcome. $\boldsymbol{A}, \boldsymbol{B}$, Representative TEM images of an MSB ( $\boldsymbol{A})$ and perforated synapse (PS; $\boldsymbol{B}$ ). Boutons forming synaptic contacts with more than one postsynaptic element ( $\boldsymbol{A}$, arrows) were identified as MSBs. Synapses with perforated or segmented postsynaptic densities ( $\boldsymbol{B}$, arrowheads) were identified as PSs. Scale bar, $500 \mathrm{~nm}$. C, Lesion animals that received rehabilitative training (RT) had greater densities of MSB synapses and PSs compared with sham-operated animals. $\boldsymbol{D}, \boldsymbol{E}$, Similar to the overall densities of MSBs and PSs $(\boldsymbol{C})$, the numbers of MSBs and PSs per dendritic unit volume $(\boldsymbol{D})$ and surface area $(\boldsymbol{E})$ were increased in the Les + RT group compared with sham-operated animals. The number of MSBs per dendritic surface area was significantly increased as a result of rehabilitative training in animals with lesions (Les + CTL vs Les + RT). $\boldsymbol{F}$, Correlations between the density of PSs and reaching performance. Although there was no significant correlation observed in sham animals, PS density was significantly correlated with functional outcome after lesions, as measured by the percentage of successful reach attempts. ${ }^{*} p<0.05,{ }^{* *} p<0.01,{ }^{* * *} p<0.001$. n.S., Not significant.

membrane apposed with synapses/ $\sum$ surface density of astrocytic process membrane) was increased as a result of both reach training and lesions. Postoperative reach training in shams (i.e., practice of the motor skill that was established preoperatively) increased the proportion of astrocytic membrane apposed to synapses significantly (Sham $+\mathrm{RT}$ vs Sham $+\mathrm{CTL}, F_{(1,14)}=$ $6.26, p=0.025$; Fig. $5 B$ ) even though this training did not influence behavioral performance or synapse densities in this group. In addition, ischemic lesions increased astrocytic membrane apposed to synapses in comparison with training-matched sham groups (Sham+CTL vs Les+CTL, $F_{(1,15)}=13.4, p=0.003$; Sham + RT vs Les + RT, $\left.F_{(1,15)}=4.60, p=0.049\right)$. Animals that underwent rehabilitative reach training after lesions (Les+RT) tended to have a greater percentage of astrocytic membrane apposed to synapses than no-rehabilitative training controls with lesions (Les + CTL), but this did not reach statistical significance $\left(F_{(1,16)}=3.10, p=0.097\right)$. The overall volume fraction and surface density of astrocytic processes were similar across groups (Table 1). Although the proportion of astrocytic membrane apposed to synaptic elements varied with training and lesion condition, the mean astrocytic coverage per synapse did not (Table 1). Perforated synapses, a subtype that was significantly associ- ated with functional outcomes after lesions, had greater surface area of astrocytic coverage (Fig. 5C) and a greater proportion of perforated synapses had astrocytic contacts (Fig. 5D) than the overall synapse population. The effects did not vary significantly across groups $(p>0.05)$. Together, these data indicate that both lesions and reach training repositioned astrocytic processes to be apposed with synapses and that the increased synaptic density resulted from poststroke rehabilitative training was accompanied by a complementary amount of apposing astrocytic processes.

We next addressed the question of whether the repositioning of astrocytic processes apposed to synapses is relevant to functional outcome. The percentage of synapses with direct astrocytic contacts onto presynaptic or postsynaptic elements or the axondendritic junction was significantly correlated with reaching performance averaged over the last 2 weeks of the 4 week rehabilitative training period in animals with lesions $(r=0.58, p=$ $0.011)$, but not in sham-operated animals $(r=-0.27, p=0.320$, two-tailed; Fig. $5 E$ ). Overall, these results indicate that rehabilitative training induces the repositioning of perisynaptic astrocytes in coordination with synaptic structural changes in peri-infarct cortex and that these effects are tightly associated with poststroke functional outcomes. 
A

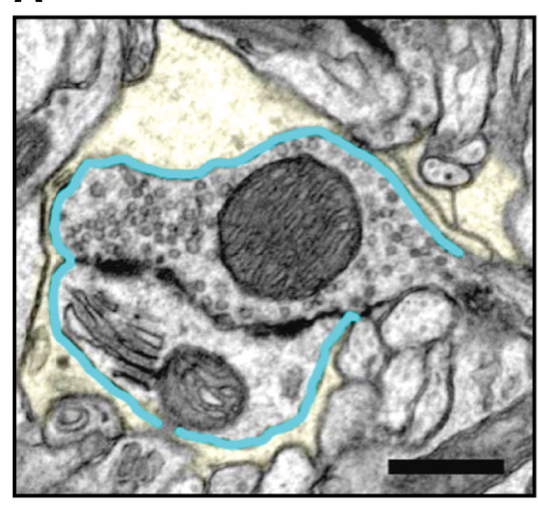

B

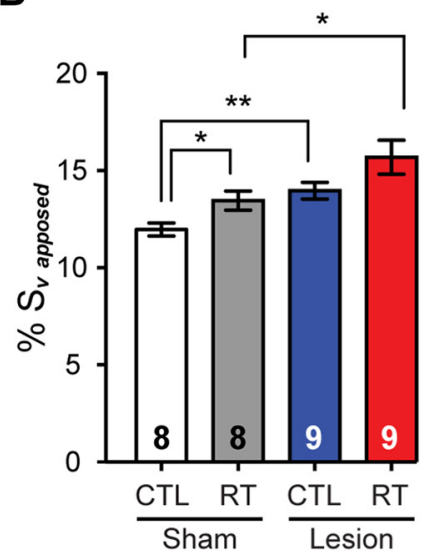

C

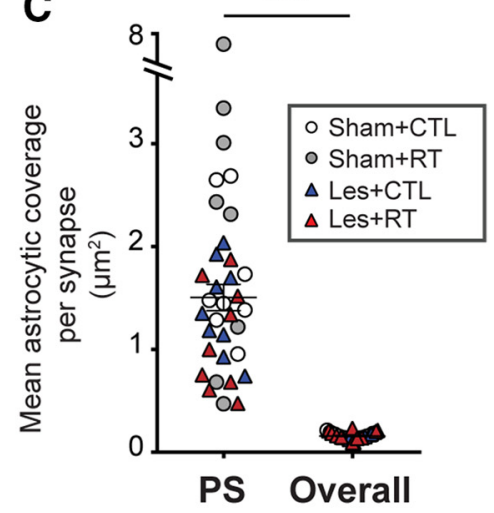

E

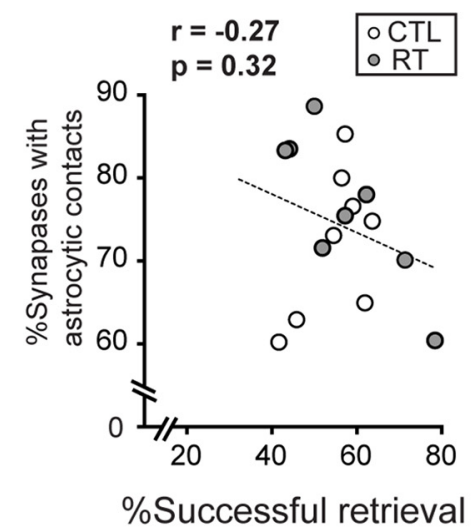

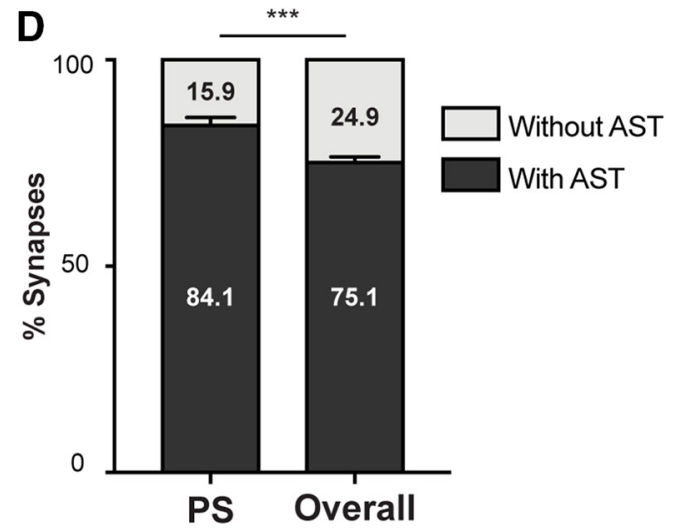

Lesion

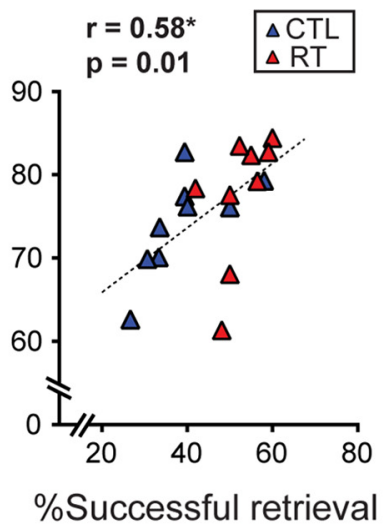

Figure 5. Astrocytic apposition to synapses was increased as a result of reaching practice and lesions and was predictive of functional outcome. $\boldsymbol{A}$, Representative TEM image containing perisynaptic astrocytes (yellow). Perisynaptic astrocytic membranes were identified as those directly apposed with synaptic elements (blue outline). Scale bar, $500 \mathrm{~nm}$. $\boldsymbol{B}$, Proportion of astrocytic membrane apposed to synapses (\%Svapposed $)$ was increased as a result of postoperative reach training and lesions. In sham-operated animals, the percentage of astrocytic apposition with synapses was slightly increased as a result of reach training (Sham + CTL vs Sham + RT). In training-matched comparisons (Sham + CTL vs Les + CTL and Sham + RT vs Les + RT), lesioned groups had a greater percentage of astrocytic apposition around synapses. $\boldsymbol{C}, \boldsymbol{D}$, Compared with the overall population of axodendritic synapses, across all groups, perforated synapses had greater mean surface area of astrocytic coverage $(\boldsymbol{C})$ and a larger proportion of perforated synapses had direct astrocytic contacts on their synaptic elements $(\boldsymbol{D})$. $\boldsymbol{E}$, Although there was no significant correlation between the percentage of synapses with astrocytic contacts and reaching performance in sham-operated animals, postinfarct functional outcome was significantly correlated with the proportion of synapses with direct astrocytic contacts. ${ }^{*} p<0.05,{ }^{* *} p<0.01$, ${ }^{* * *} p<0.001,{ }^{* * *} p<0.0001$.

Protein synthesis inhibition in the CFA core, but not the CFA border, resulted in a loss of established motor skills in intact animals

Our finding that postinfarct training induced synaptic structural changes in the border region of the residual CFA raised the question of whether this region is a key anatomical substrate for the training-induced motor functional improvements. To address this, we first tested the importance of this border region for forelimb motor skills in intact animals. The maintenance of an established reaching skill has been found previously to be dependent on continued protein synthesis in the CFA (Kleim et al., 2003b). When infused into the center of the CFA, the protein synthesis inhibitor ANI results in a transient loss of established motor skills in intact animals in the absence of obvious neuronal pathology or motor behavioral dysfunction (Kleim et al., 2003b). Therefore, we compared the effects on skilled reaching function of ANI infusions into the center of the CFA ("core") versus its anteromedial border, the same region as the TEM samples in the present study (Fig. 3A).

Intact rats were first trained to a performance plateau on the reaching task and then received implantation of cannulae in the CFA core or border region (Fig. 6A). Cannula implantation alone did not disrupt skilled reaching performance, as assayed in two testing sessions (Fig. 6B). Groups then received infusions of VEH (ACSF), $50 \mu \mathrm{g} / \mu \mathrm{l} \mathrm{ANI}$, and $100 \mu \mathrm{g} / \mu \mathrm{l}$ ANI in three separate testing sessions (Fig. 6A). There was a significant drug condition $\times$ cortical location interaction $\left(F_{(2,22)}=12.79, p=0.0002\right)$. Reaching success was reduced significantly at 2 and $24 \mathrm{~h}$ after $100 \mu \mathrm{g}$ of ANI into the CFA core, but not the border, compared with VEH (Fig. 6B). Reaching success returned to normal by $48 \mathrm{~h}$ after injections. There were no significant effects after $50 \mu \mathrm{g}$ ANI infusions into the core $(p>0.05)$. These results confirm the importance of a normal functioning CFA core for the maintenance of established reaching skill in intact animals and indicate that its border region is not essential for the same skill.

ANI infusion in the CFA core diminished forelimb movement representations and synaptic density in the CFA core of intact animals

The effects on motor skills of ANI infusions in the CFA core have been linked previously with reductions in forelimb movement representation area and synapse density in layer $\mathrm{V}$ of the CFA (Kleim et al., 2003b). To compare the effects of infusions in the 
A
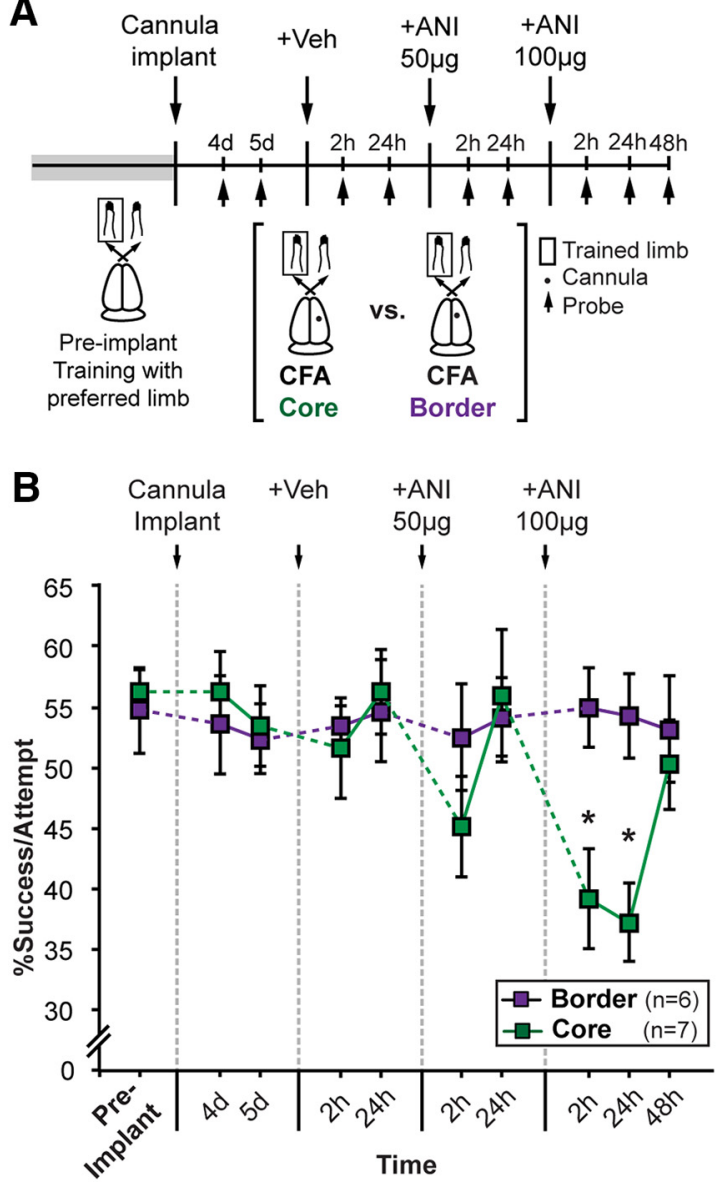

Figure 6. ANI infused in the core, but not border, region of the CFA disrupted established reaching skill in intact animals. A, Experimental design. Rats were trained to a plateau on a skilled reaching task and then received cannula implantation surgeries that targeted either the core or border of the CFA in the motor cortex contralateral to the trained forelimb. ACSF VEH, $50 \mu \mathrm{g}$ of ANI, and $100 \mu \mathrm{g}$ of ANI were infused sequentially, each $2 \mathrm{~d}$ apart, before performance of the skilled reaching task. $\boldsymbol{B}$, Reaching performance was disrupted 2 and $24 \mathrm{~h}$ after infusion of $100 \mu \mathrm{g}$ of ANI in the CFA core until $48 \mathrm{~h}$ after infusions. ${ }^{*} p<0.05$, ${ }^{* *} p<0.01$ versus VEH. This was not found after ANI infusions in the border or infusion of $50 \mu \mathrm{g}$ of ANI in the core.

CFA core versus border on motor cortical organization, ICMS was used to delineate forelimb movement representations in naive rats and then the same regions were remapped after infusions. ANI $(100 \mu \mathrm{g})$ infusions in the CFA core resulted in a major loss of forelimb movement representations in both the CFA and RFA compared with VEH infusions (Fig. $7 A, B$ ). The magnitude of the change in forelimb movement representations varied depending on the preinfusion (baseline) area of these representations within a $1.5 \mathrm{~mm}$ radius from the center of the infusion, but not outside of this radius (Fig. 7C), consistent with localized infusion effects found in previous studies (Wanisch and Wotjak, 2008; Sharma et al., 2012). Although ANI infusions in the CFA border tended to reduce forelimb representation area, this was not statistically significant compared with VEH infusions. We additionally confirmed that ANI infusion into the CFA core reduced synaptic density in layer $\mathrm{V}$ of the same region compared with the contralateral hemisphere of the same animals after VEH infusions (Fig. 7D). In contrast, synaptic density was not reduced in the border region as a result of ANI infusions in the CFA core, confirming its localized effect on synaptic connectivity. Therefore, the effect on skilled reaching of ANI infusions into the CFA core, but not border, is explainable by the more severe impact of the former on movement representations and synaptic connectivity in the CFA core, which is more essential for forelimb skills in intact animals.

\section{After CFA infarcts, protein synthesis inhibition in the CFA border resulted in the loss of rehabilitative-training-induced functional gains}

We next used ANI infusions to test the role of the CFA border in the maintenance of relearned reaching skill after CFA lesions (Fig. 8). Note that the CFA border is the region where synaptic densities (Fig. 3) and forelimb movement representations (Kim et al., 2015) were increased after rehabilitative training. After the lesions and cannula implantations, rats received motor rehabilitative training as in the previous experiment for 3 weeks. As shown in Figure $8 C$, skilled reaching performance improved significantly during rehabilitative training (time effect: $F_{(3,51)}=$ $21.85, p<0.0001)$. A small set of no-rehabilitative training controls $(n=4)$ had no significant functional improvement, which was consistent with the previous experiment. ANI, but not VEH, infusion into the CFA border reinstated functional impairments. This was not found with infusions of VEH into the same region nor after ANI infusion into posterior parietal cortex (ANI-Par). Repeated-measures ANOVA with group (VEH, ANI-Par, ANIBorder) and drug condition (post-VEH and post-ANI probes) as factors revealed a significant group $\times$ drug condition interaction effect $\left(F_{(2,17)}=22.23, p<0.0001\right)$. Post hoc analyses indicated significantly greater disruption of skilled reaching performance after ANI infusions into the CFA border compared with both with VEH infusions (VEH-Border) and ANI infusions in parietal cortex (ANI-Par). Although ANI infusions tended to reduce performance in the No-RT group, this effect was not significant compared with the post-VEH infusion time point ( $p=0.08)$, in contrast to its significant effects after rehabilitative training ( $p<$ 0.001 ). Infarct sizes were not significantly different among the three groups (mean \pm SE cortical volume loss: $7.67 \pm 1.83 \mathrm{~mm}^{3}$ in ANI-Border, $7.74 \pm 2.20 \mathrm{~mm}^{3}$ in VEH, and $5.71 \pm 1.17 \mathrm{~mm}^{3}$ in ANI-Par). These findings corroborate that functional vicariation occurred in the CFA border region due to postinfarct rehabilitative training and mediated the training-induced motor functional improvements.

\section{Discussion}

Motor rehabilitative training after subtotal motor cortical infarcts can drive the maintenance, reemergence, and reorganization of movement representations in remaining cortex (Nudo et al., 1996; Friel et al., 2000; Conner et al., 2005; Ramanathan et al., 2006; Kim et al., 2015; Tennant et al., 2015). The present findings indicate that rehabilitative training also drives remaining motor cortex to increase and mature its synaptic connectivity substantially along with coordinated repositioning of astrocytic processes. That ANI infusions, which diminished synapse quantities, reinstated functional deficits corroborates that these synaptic structural changes are a potential mechanism by which remaining cortex comes to mediate lost function.

Without rehabilitative training, animals with infarcts had persistent functional deficits despite the fairly small size of infarcts and a comparable peri-infarct synapse density to sham-operated rats. The latter is consistent with findings that, after an initial loss of spines in peri-infarct cortex, spine density is restored by increased spine formation (Brown et al., 2007; Brown et al., 2008). Although rehabilitative training increased it, the overall density of synapses in peri-infarct cortex was not strongly correlated 
A

PRE

POST

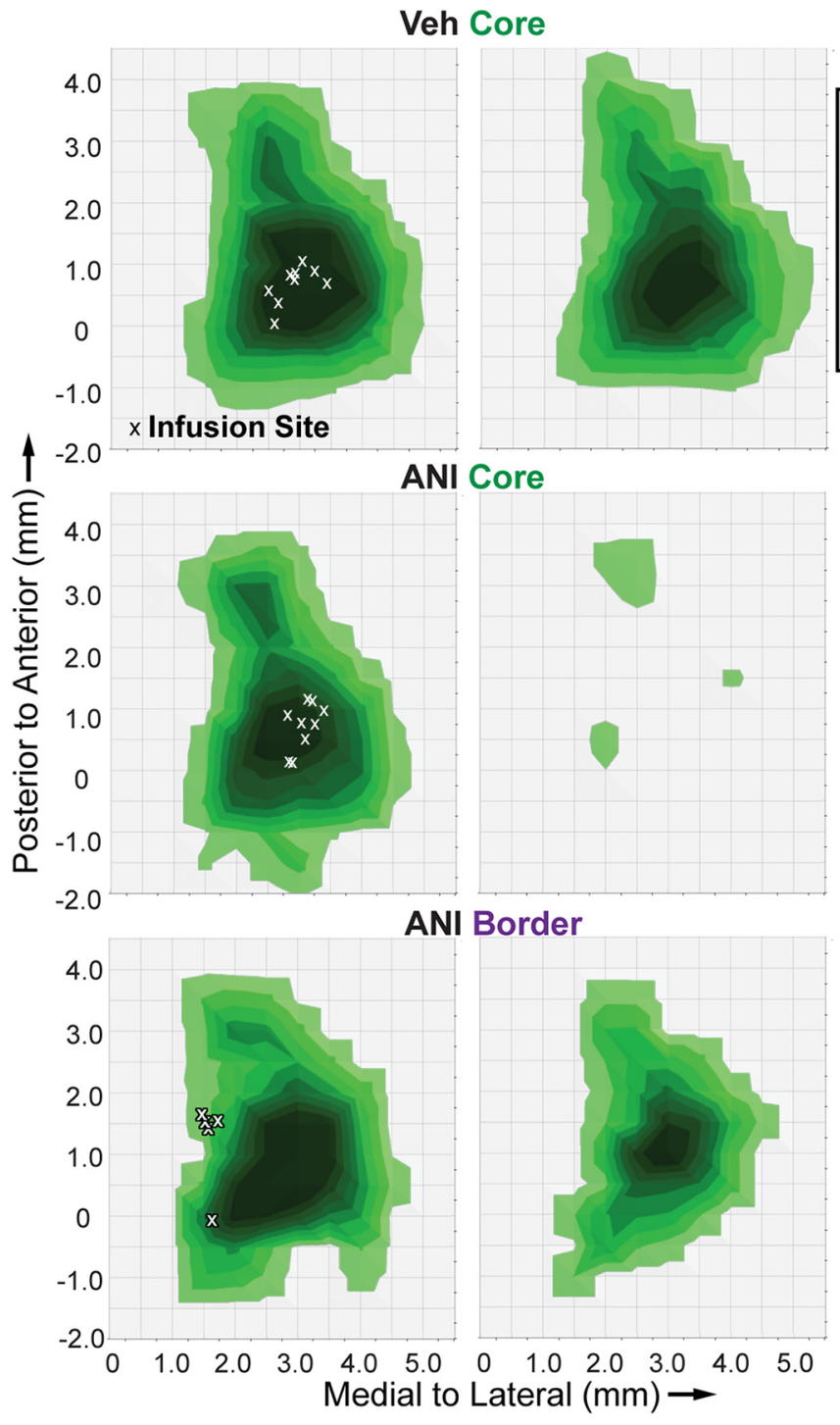

B

CFA

RFA

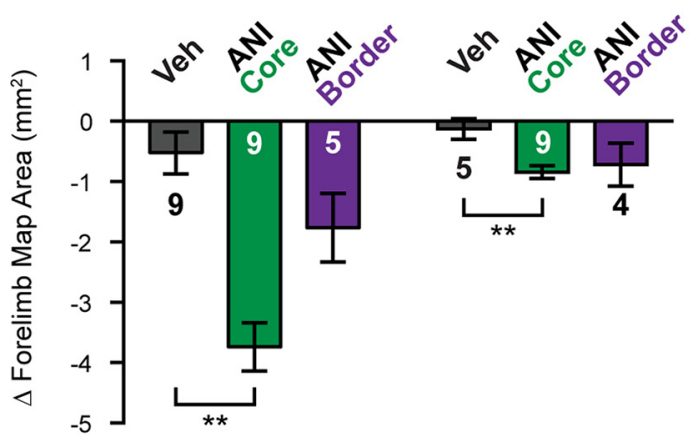

C

$\leq 1.5 \mathrm{~mm}$

$>1.5 \mathrm{~mm}$

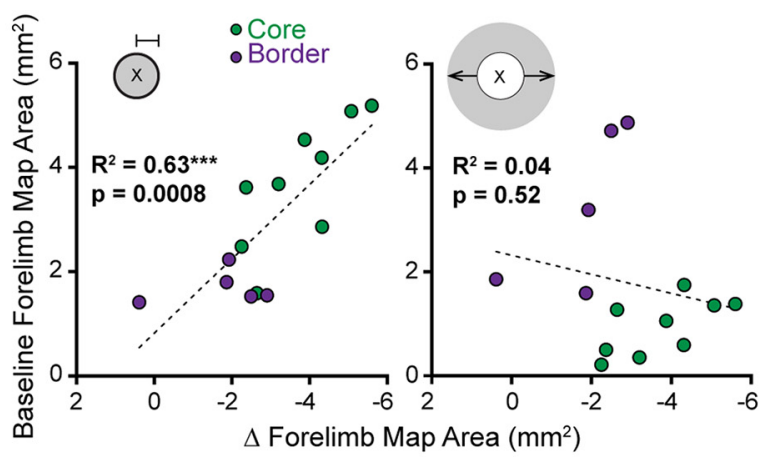

D

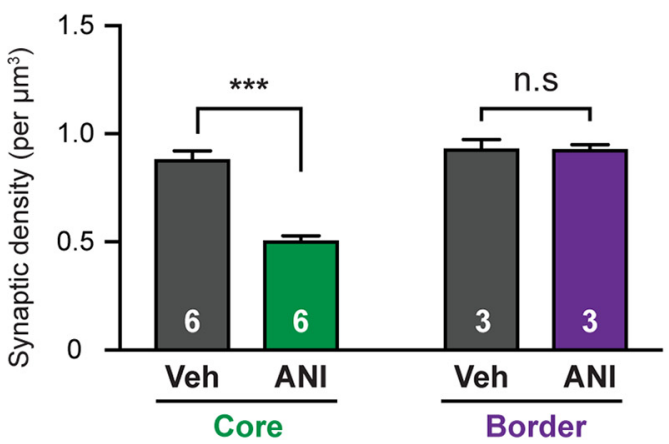

Figure 7. ANI infusions in the CFA core decreased forelimb movement representation area and synaptic density in the CFA core, but not border region. $\boldsymbol{A}, \boldsymbol{B}$, Effects of $100 \mu \mathrm{g}$ ANI infusions in the CFA core on forelimb motor maps, as assayed with intracortical microstimulation in naive rats. Surface plots in $\boldsymbol{A}$ show the mean percentage area of forelimb movement representations per $0.5 \times$ $0.5 \mathrm{~mm}$ grid square. After infusions of ANI in the CFA core, forelimb representations in both the CFA and RFA were significantly reduced compared with VEH infusions. The effects of border infusions of ANI were not significant compared with VEH ( $p=0.15)$. $\Delta$ Forelimb map area was calculated as differences between preinfusions and postinfusions (POST - PRE). $C$, Correlations between baseline forelimb map area versus the degree of reduction in forelimb map area after drug infusion. The magnitude of the effect of ANI in reducing forelimb representation was significantly correlated with the baseline area of these representations within a $1.5 \mathrm{~mm}$ radius from the infusion site (left), but not outside of this radius (right). D, Synaptic density in layer $V$ after ANI or VEH infusions in the CFA core, as measured in a subset of animals after ICMS mapping. ANI resulted in a major reduction in synaptic density in the CFA core compared with the contralateral VEH-infused hemisphere of the same animals. Synaptic density in the CFA border was unaffected by ANI infusions in the CFA core. The numbers within the bars indicate the number of animals per group. ${ }^{* *} p<0.01$, *** $p<0.001$.

with functional improvements. Therefore, overall synapse and spine quantities in peri-infarct tissue presumably reflect the magnitude of postinfarct structural plasticity, but they are not a conclusive indicator of functional improvements. In contrast, perforated synapse density and astrocytic coverage of synapses in peri-infarct cortex were strongly predictive of functional improvements.

Perforated synapses increase in association with long-term potentiation in motor cortex (Connor et al., 2006) and they contain more AMPA receptors, larger postsynaptic densities (Ganeshina et al., 2004), and more presynaptic docked and reserve pool vesicles (Nava et al., 2014) than simple synapses, supporting their greater efficacy. Perforated synapses, as well MSBs, are in- creased in response to motor learning in intact animals (Kleim et al., 2003a), consistent with the training-induced amplification of their addition in peri-infarct cortex reflecting learning-related processes. Motor training in intact animals also induces spine formation in clusters on apical dendrites of layer $\mathrm{V}$ pyramidal neurons, with the first new spine of a cluster being strengthened in association with the addition of the neighbor (Fu et al., 2012). Therefore, it is possible that the increased densities of MSBs and perforated synapses observed in the present study reflect synapse clustering and strengthening. MSBs often include immature synapses (Li et al., 2011) and their presence can reflect the process of selective synapse strengthening and weakening (Lee et al., 2013b). 

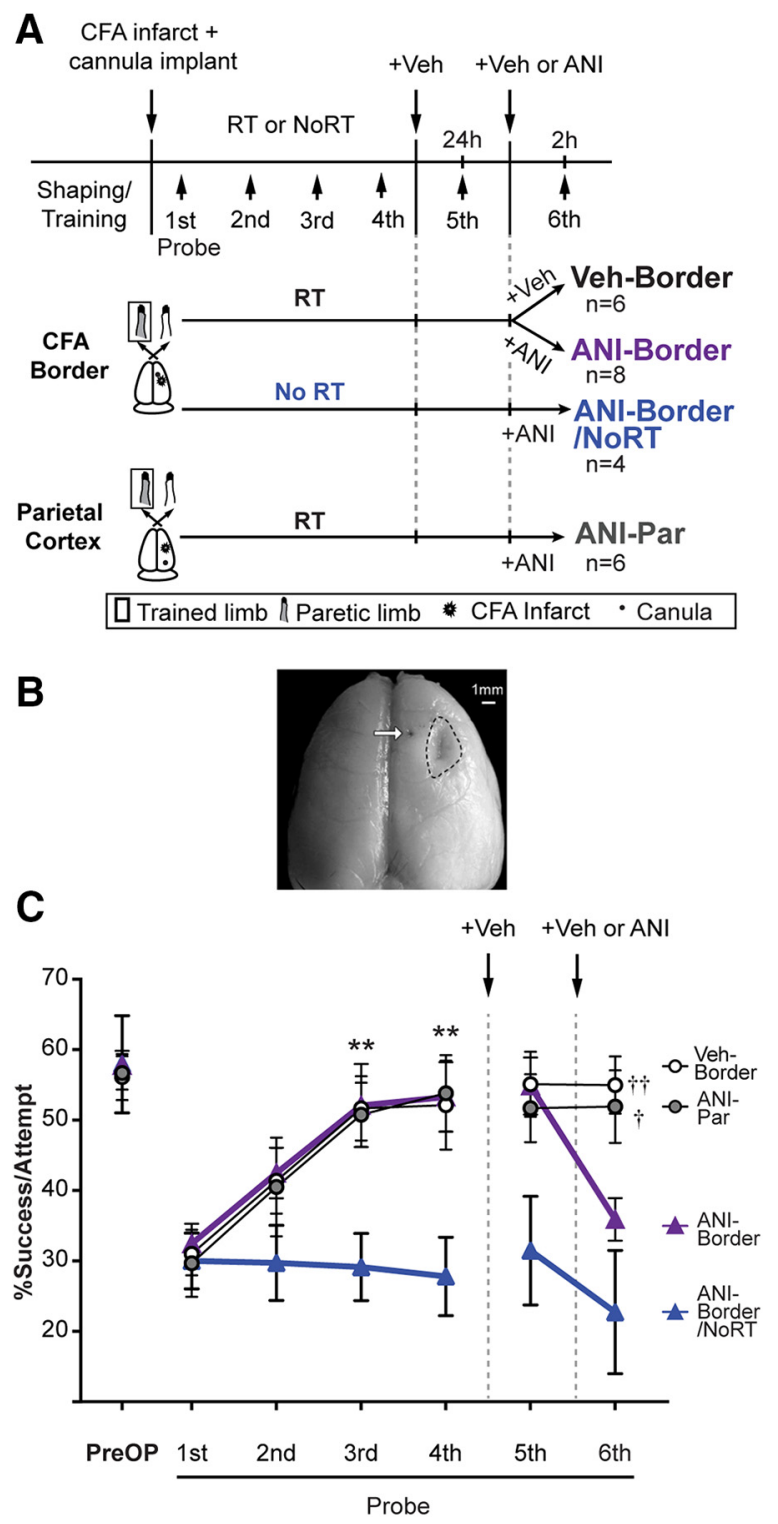

Figure 8. ANl infusions in the CFA border attenuated performance improvements achieved with postinfarct rehabilitative training. $A$, Summary of experimental design. Rats received CFA infarcts and implantation of superficial guide cannulae over the CFA border or over the parietal cortex. At the end of the rehabilitative training period, reaching performance was tested after VEH and ANI infusions in peri-infarct (ANI-Border) or parietal (ANI-Par) cortex. B, Lesion (dashed outline) and cannulae track in the (FA border (arrow) in a perfusion fixed cerebrum. C, Percentage of successful retrievals in the skilled reaching task. The three groups that received rehabilitative training had better reaching performances on probes 3 and 4 compared with controls without rehabilitative training. ANI infusions in the CFA border negated the improved reaching performance on probe 6 compared with both VEH infusions in the CFA border and ANI infusions in parietal cortex. ${ }^{* *} p<0.01$ versus ANI-Border/NoRT; $\uparrow p<0.05$, $\dagger+p<0.01$ versus ANI-Border.

This may explain why quantities of perforated synapses were more strongly correlated with functional outcome than those of MSBs. We found previously that a manipulation that diminishes rehabilitative training efficacy (prior training of the nonparetic forelimb) is linked with increases in MSBs, but not perforated synapses, in the peri-infarct cortex (Kim et al., 2015). Together, these findings point more strongly to synapse maturation than to synapse addition in peri-infarct cortex as a neural underpinning of poststroke functional improvement.

Rehabilitative training induced astrocytic repositioning in accordance with synaptic structural changes in peri-infarct cortex.
As spine structural changes occur, perisynaptic astrocytic processes change their apposition around synapses in an activitydependent manner (Haber et al., 2006; Perez-Alvarez et al., 2014), which promotes excitatory synapse stability (Bernardinelli et al., 2014). They also regulate spine morphology and transmission by membrane-bound signaling (Murai et al., 2003; Carmona et al., 2009; Filosa et al., 2009). Therefore, perisynaptic astrocytes can be expected to help establish and promote the functional integrity of remodeling circuitry. Given that astrocytes were also tightly associated with perforated synapses in periinfarct cortex, as reflected in greater coverage and more frequent direct contacts with perforated synapses than the overall population, and that both the density of perforated synapses and the percentage of synapses with direct astrocytic contacts were strongly predictive of functional outcome, it seems reasonable to postulate interdependencies between the perisynaptic astrocytic responses and synaptic responses to rehabilitative training. Astrocytes also mediate, directly or indirectly, synaptic pruning in an activity-dependent way (Yu et al., 2013) (Chung et al., 2013) such that it also plausible that changes in perisynaptic astrocytes influence synaptic clustering and selective strengthening. Future study is warranted to elucidate how peri-infarct synaptic refinement processes are orchestrated with perisynaptic astrocytes and how rehabilitative training shapes this process.

Although the afferent sources of the synapses examined in this study are diverse, activity-dependent plasticity of intrinsic horizontal connections may play a major role in map reorganization (Sanes and Donoghue, 2000). Furthermore, there is considerable sprouting of corticocortical afferents into peri-infarct cortex (Dancause et al., 2005; Overman et al., 2012; Clarkson et al., 2013). The sprouting and maturation of new intracortical and intrinsic connections seem to be influenced by motor rehabilitative training after CFA infarcts. Consistent with this, the sprouting of descending efferents of remaining motor cortex is increased by reach training after cortical infarcts (Lee et al., 2013a) and by forced paretic limb use after intracerebral hemorrhage (Ishida et al., 2016). The behavioral effects of postinfarct treatments that promote axonal sprouting (Fang et al., 2010; Wahl et al., 2014) and increase cortical synapse density (Adkins-Muir and Jones, 2003; Adkins et al., 2008) are also enhanced by their combination with motor rehabilitative training. Overman et al. (2012) found that the intracortical axonal sprouting responses to one such treatment (ephrin A5 blockade) were greatly amplified by forced use of the paretic forelimb.

ANI infusions in the CFA core of intact rats disrupted established reaching skills and caused a major loss of forelimb representations, as revealed by ICMS. This replicates findings by Kleim et al. (2003b) using ANI and cycloheximide, although Luft et al. (2004) showed that the same dose of ANI $(100 \mu \mathrm{g})$ in motor cortex impairs motor skill learning without disrupting established skills. ANI at this dose also silences neural activity in hippocampus (Sharma et al., 2012), but not at lower doses (Remaud et al., 2014). However, it does not lead to neuron death or frank neuropathology in either cortex or hippocampus (Kleim et al., 2003b; Sharma et al., 2012). Our study differed from that of Kleim et al. (2003b) by examining synapses soon (1-4 h) after ANI infusions compared with $4 \mathrm{~d}$ in their study. The rapidity with which synapse density was decreased by ANI infusions is consistent with its induction of synapse retraction, but this does not rule out effects on synapse turnover rates as well. Local protein synthesis promotes transmitter biogenesis and receptor expression in neurons (Jung et al., 2012) and rapid and localized translational changes in synaptic elements (Sutton and Schu- 
man, 2006; Jung et al., 2012). Further study is needed to understand the mechanism by which its acute inhibition diminishes synapse quantities. Our findings nevertheless add to the caveats on using protein synthesis inhibitors as selective blockers of synaptic plasticity (Gold, 2008).

Although ANI infusions in the CFA border of intact animals did not affect forelimb representations or established motor skills significantly, infusions in this region after CFA infarcts negated the functional improvements achieved with rehabilitative training. These findings support that the reorganized cortex proximal to the infarct is necessary for the maintenance of traininginduced performance improvements. The synaptic plasticity found in this region could mediate the reinstatement of neural integrity and circuitry reorganization that underlies the functional improvements.

The motor map reorganization that is driven by rehabilitative training has been linked to both recovery of more normal movements and new compensatory strategies for task completion (Friel and Nudo, 1998; Whishaw, 2000; Metz et al., 2005; O’Bryant et al., 2016). In the present study, rehabilitative training promoted the recovery of more normal movements. Although this does not rule out that new compensatory strategies also contributed to performance improvements, it seems reasonable to consider the experience-dependent synaptic plasticity that we observed in peri-infarct cortex to be a putative recovery mechanism. To our knowledge, these studies are the first to show an increase in synaptic density, efficacious synaptic subtypes, and astrocytic apposition, as measured by quantitative electron microscopy, in a region of peri-infarct cortex that was driven to support improved function as a result of rehabilitative training. That the improved function can be disrupted by ANI suggests that the structural and functional integrity of the reorganized cortex plays an important role in recovered function. Although the present findings support the necessity of this area, they do not indicate sufficiency. It is likely that rehabilitative-training-induced synaptic plasticity in the peri-infarct cortex represents merely one aspect of reorganization across somatosensory and motor networks that supports improved function (Nudo, 2013; Jones and Adkins, 2015; Jones, 2017). The contribution of remaining cortical areas to functional improvements probably varies with time (Carmichael, 2006) and stroke loci and severities, depending on proximity and shared connectivity. It also seems reasonable to assume that the changes that we observed in layer $\mathrm{V}$ were not confined to this layer, especially given the profound spine remodeling observed on superficial dendrites in peri-infarct cortex (Brown et al., 2007; Brown et al., 2008; Mostany et al., 2010; Wang et al., 2016). Further investigation is necessary to determine the mechanisms responsible for the structural plasticity and its intercoordination with changes in other brain regions and to determine how these effects vary across the heterogeneity of stroke.

\section{References}

Adams FS, Schwarting RK, Huston JP (1994) Behavioral and neurochemical asymmetries following unilateral trephination of the rat skull: is this control operation always appropriate? Physiol Behav 55:947-952. CrossRef Medline

Adkins DL, Voorhies AC, Jones TA (2004) Behavioral and neuroplastic effects of focal endothelin-1 induced sensorimotor cortex lesions. Neuroscience 128:473-486. CrossRef Medline

Adkins DL, Hsu JE, Jones TA (2008) Motor cortical stimulation promotes synaptic plasticity and behavioral improvements following sensorimotor cortex lesions. Exp Neurol 212:14-28. CrossRef Medline

Adkins-Muir DL, Jones TA (2003) Cortical electrical stimulation combined with rehabilitative training: enhanced functional recovery and dendritic plasticity following focal cortical ischemia in rats. Neurol Res 25:780-788. CrossRef Medline

Allred RP, Kim SY, Jones TA (2014) Use it and/or lose it-experience effects on brain remodeling across time after stroke. Front Hum Neurosci 8:379. CrossRef Medline

Bernardinelli Y, Randall J, Janett E, Nikonenko I, König S, Jones EV, Flores CE, Murai KK, Bochet CG, Holtmaat A, Muller D (2014) Activitydependent structural plasticity of perisynaptic astrocytic domains promotes excitatory synapse stability. Curr Biol 24:1679-1688. CrossRef Medline

Biernaskie J, Corbett D (2001) Enriched rehabilitative training promotes improved forelimb motor function and enhanced dendritic growth after focal ischemic injury. J Neurosci 21:5272-5280. Medline

Braun RG, Andrews EM, Kartje GL (2012) Kinematic analysis of motor recovery with human adult bone marrow-derived somatic cell therapy in a rat model of stroke. Neurorehabil Neural Repair 26:898-906. CrossRef Medline

Brown CE, Li P, Boyd JD, Delaney KR, Murphy TH (2007) Extensive turnover of dendritic spines and vascular remodeling in cortical tissues recovering from stroke. J Neurosci 27:4101-4109. CrossRef Medline

Brown CE, Wong C, Murphy TH (2008) Rapid morphologic plasticity of peri-infarct dendritic spines after focal ischemic stroke. Stroke 39:12861291. CrossRef Medline

Carmichael ST (2003) Plasticity of cortical projections after stroke. Neuroscientist 9:64-75. CrossRef Medline

Carmichael ST (2006) Cellular and molecular mechanisms of neural repair after stroke: making waves. Ann Neurol 59:735-742. CrossRef Medline

Carmichael ST (2012) Brain excitability in stroke: the yin and yang of stroke progression. Arch Neurol 69:161-167. CrossRef Medline

Carmona MA, Murai KK, Wang L, Roberts AJ, Pasquale EB (2009) Glial ephrin-A3 regulates hippocampal dendritic spine morphology and glutamate transport. Proc Natl Acad Sci U S A 106:12524-12529. CrossRef Medline

Carrera E, Tononi G (2014) Diaschisis: past, present, future. Brain 137: 2408-2422. CrossRef Medline

Castro-Alamancos MA, Borrel J (1995) Functional recovery of forelimb response capacity after forelimb primary motor cortex damage in the rat is due to the reorganization of adjacent areas of cortex. Neuroscience 68: 793-805. CrossRef Medline

Cho J, Kwon DH, Kim RG, Song H, Rosa-Neto P, Lee MC, Kim HI (2016) Remodeling of neuronal circuits after reach training in chronic capsular stroke. Neurorehabil Neural Repair 30:941-950. CrossRef Medline

Chung WS, Clarke LE, Wang GX, Stafford BK, Sher A, Chakraborty C, Joung J, Foo LC, Thompson A, Chen C, Smith SJ, Barres BA (2013) Astrocytes mediate synapse elimination through MEGF10 and MERTK pathways. Nature 504:394-400. CrossRef Medline

Clarkson AN, López-Valdés HE, Overman JJ, Charles AC, Brennan KC, Thomas Carmichael S (2013) Multimodal examination of structural and functional remapping in the mouse photothrombotic stroke model. J Cereb Blood Flow Metab 33:716-723. CrossRef Medline

Conner JM, Chiba AA, Tuszynski MH (2005) The basal forebrain cholinergic system is essential for cortical plasticity and functional recovery following brain injury. Neuron 46:173-179. CrossRef Medline

Connor S, Williams PT, Armstrong B, Petit TL, Ivanco TL, Weeks AC (2006) Long-term potentiation is associated with changes in synaptic ultrastructure in the rat neocortex. Synapse 59:378-382. CrossRef Medline

Dancause N, Barbay S, Frost SB, Plautz EJ, Chen D, Zoubina EV, Stowe AM, Nudo RJ (2005) Extensive cortical rewiring after brain injury. J Neurosci 25:10167-10179. CrossRef Medline

Fang PC, Barbay S, Plautz EJ, Hoover E, Strittmatter SM, Nudo RJ (2010) Combination of NEP 1-40 treatment and motor training enhances behavioral recovery after a focal cortical infarct in rats. Stroke 41:544-549. CrossRef Medline

Feeney DM, Baron JC (1986) Diaschisis. Stroke 17:817-830. CrossRef Medline

Fiala JC (2005) Reconstruct: a free editor for serial section microscopy. J Microsc 218:52-61. CrossRef Medline

Filosa A, Paixão S, Honsek SD, Carmona MA, Becker L, Feddersen B, Gaitanos L, Rudhard Y, Schoepfer R, Klopstock T, Kullander K, Rose CR, Pasquale EB, Klein R (2009) Neuron-glia communication via EphA4/ ephrin-A3 modulates LTP through glial glutamate transport. Nat Neurosci 12:1285-1292. CrossRef Medline

Friel KM, Nudo RJ (1998) Recovery of motor function after focal cortical 
injury in primates: compensatory movement patterns used during rehabilitative training. Somatosens Mot Res 15:173-189. CrossRef Medline

Friel KM, Heddings AA, Nudo RJ (2000) Effects of postlesion experience on behavioral recovery and neurophysiologic reorganization after cortical injury in primates. Neurorehabil Neural Repair 14:187-198. CrossRef Medline

Fu M, Yu X, Lu J, Zuo Y (2012) Repetitive motor learning induces coordinated formation of clustered dendritic spines in vivo. Nature 483:92-95. CrossRef Medline

Fuxe K, Bjelke B, Andbjer B, Grahn H, Rimondini R, Agnati LF (1997) Endothelin-1 induced lesions of the frontoparietal cortex of the rat: a possible model of focal cortical ischemia. Neuroreport 8:2623-2629. CrossRef Medline

Ganeshina O, Berry RW, Petralia RS, Nicholson DA, Geinisman Y (2004) Synapses with a segmented, completely partitioned postsynaptic density express more AMPA receptors than other axospinous synaptic junctions. Neuroscience 125:615-623. CrossRef Medline

Geinisman Y, Gundersen HJ, van der Zee E, West MJ (1996) Unbiased stereological estimation of the total number of synapses in a brain region. J Neurocytol 25:805-819. CrossRef Medline

Gold PE (2008) Protein synthesis inhibition and memory: formation vs amnesia. Neurobiol Learn Mem 89:201-211. CrossRef Medline

Gundersen HJ, Bendtsen TF, Korbo L, Marcussen N, Møller A, Nielsen K, Nyengaard JR, Pakkenberg B, Sørensen FB, Vesterby A (1988) Some new, simple and efficient stereological methods and their use in pathological research and diagnosis. Apmis 96:379-394. CrossRef Medline

Haber M, Zhou L, Murai KK (2006) Cooperative astrocyte and dendritic spine dynamics at hippocampal excitatory synapses. J Neurosci 26:88818891. CrossRef Medline

Hsu JE, Jones TA (2005) Time-sensitive enhancement of motor learning with the less-affected forelimb after unilateral sensorimotor cortex lesions in rats. Eur J Neurosci 22:2069-2080. CrossRef Medline

Hsu JE, Jones TA (2006) Contralesional neural plasticity and functional changes in the less-affected forelimb after large and small cortical infarcts in rats. Exp Neurol 201:479-494. CrossRef Medline

Ishida A, Isa K, Umeda T, Kobayashi K, Kobayashi K, Hida H, Isa T (2016) Causal link between the cortico-rubral pathway and functional recovery through forced impaired limb use in rats with stroke. J Neurosci 36:455467. CrossRef Medline

Johansson BB (2000) Brain plasticity and stroke rehabilitation: the Willis Lecture. Stroke 31:223-230. CrossRef Medline

Jones TA (2017) Motor compensation and its effects on neural reorganization after stroke. Nat Rev Neurosci 18:267-280. CrossRef Medline

Jones TA, Adkins DL (2015) Motor system reorganization after stroke: stimulating and training toward perfection. Physiology (Bethesda) 30: 358-370. CrossRef Medline

Jung H, Yoon BC, Holt CE (2012) Axonal mRNA localization and local protein synthesis in nervous system assembly, maintenance and repair. Nat Rev Neurosci 13:308-324. CrossRef Medline

Kim SY, Jones TA (2010) Lesion size-dependent synaptic and astrocytic responses in cortex contralateral to infarcts in middle-aged rats. Synapse 64:659-671. CrossRef Medline

Kim SY, Jones TA (2013) The effects of ceftriaxone on skill learning and motor functional outcome after ischemic cortical damage in rats. Restor Neurol Neurosci 31:87-97. CrossRef Medline

Kim SY, Allred RP, Adkins DL, Tennant KA, Donlan NA, Kleim JA, Jones TA (2015) Experience with the "good" limb induces aberrant synaptic plasticity in the perilesion cortex after stroke. J Neurosci 35:8604-8610. CrossRef Medline

Kleim JA, Lussnig E, Schwarz ER, Comery TA, Greenough WT (1996) Synaptogenesis and Fos expression in the motor cortex of the adult rat after motor skill learning. J Neurosci 16:4529-4535. Medline

Kleim JA, Jones TA, Schallert T (2003a) Motor enrichment and the induction of plasticity before or after brain injury. Neurochem Res 28:17571769. CrossRef Medline

Kleim JA, Bruneau R, Calder K, Pocock D, VandenBerg PM, MacDonald E, Monfils MH, Sutherland RJ, Nader K (2003b) Functional organization of adult motor cortex is dependent upon continued protein synthesis. Neuron 40:167-176. CrossRef Medline

Kleim JA, Hogg TM, VandenBerg PM, Cooper NR, Bruneau R, Remple M (2004) Cortical synaptogenesis and motor map reorganization occur during late, but not early, phase of motor skill learning. J Neurosci 24: 628-633. CrossRef Medline

Lawrence ES, Coshall C, Dundas R, Stewart J, Rudd AG, Howard R, Wolfe CD (2001) Estimates of the prevalence of acute stroke impairments and disability in a multiethnic population. Stroke 32:1279-1284. CrossRef Medline

Lee KH, Kim JH, Choi DH, Lee J (2013a) Effect of task-specific training on functional recovery and corticospinal tract plasticity after stroke. Restor Neurol Neurosci 31:773-785. CrossRef Medline

Lee KJ, Park IS, Kim H, Greenough WT, Pak DT, Rhyu IJ (2013b) Motor skill training induces coordinated strengthening and weakening between neighboring synapses. J Neurosci 33:9794-9799. CrossRef Medline

Li J, Erisir A, Cline H (2011) In vivo time-lapse imaging and serial section electron microscopy reveal developmental synaptic rearrangements. Neuron 69:273-286. CrossRef Medline

Liepert J, Bauder H, Wolfgang HR, Miltner WH, Taub E, Weiller C (2000) Treatment-induced cortical reorganization after stroke in humans. Stroke 31:1210-1216. CrossRef Medline

Luft AR, Buitrago MM, Ringer T, Dichgans J, Schulz JB. (2004) Motor skill learning depends on protein synthesis in motor cortex after training. J Neurosci 24:6515-6520. CrossRef Medline

Luke LM, Allred RP, Jones TA (2004) Unilateral ischemic sensorimotor cortical damage induces contralesional synaptogenesis and enhances skilled reaching with the ipsilateral forelimb in adult male rats. Synapse 54:187199. CrossRef Medline

Metz GA, Whishaw IQ (2000) Skilled reaching an action pattern: stability in rat (Rattus norvegicus) grasping movements as a function of changing food pellet size. Behav Brain Res 116:111-122. CrossRef Medline

Metz GA, Antonow-Schlorke I, Witte OW (2005) Motor improvements after focal cortical ischemia in adult rats are mediated by compensatory mechanisms. Behav Brain Res 162:71-82. CrossRef Medline

Mostany R, Portera-Cailliau C (2011) Absence of large-scale dendritic plasticity of layer 5 pyramidal neurons in peri-infarct cortex. J Neurosci 31: 1734-1738. CrossRef Medline

Mostany R, Chowdhury TG, Johnston DG, Portonovo SA, Carmichael ST, Portera-Cailliau C (2010) Local hemodynamics dictate long-term dendritic plasticity in peri-infarct cortex. J Neurosci 30:14116-14126. CrossRef Medline

Murai KK, Nguyen LN, Irie F, Yamaguchi Y, Pasquale EB (2003) Control of hippocampal dendritic spine morphology through ephrin-A3/EphA4 signaling. Nat Neurosci 6:153-160. CrossRef Medline

Murphy TH, Corbett D (2009) Plasticity during stroke recovery: from synapse to behaviour. Nat Rev Neurosci 10:861-872. CrossRef Medline

Nava N, Chen F, Wegener G, Popoli M, Nyengaard JR (2014) A new efficient method for synaptic vesicle quantification reveals differences between medial prefrontal cortex perforated and nonperforated synapses. J Comp Neurol 522:284-297. CrossRef Medline

Neafsey EJ, Bold EL, Haas G, Hurley-Gius KM, Quirk G, Sievert CF, Terreberry RR (1986) The organization of the rat motor cortex: a microstimulation mapping study. Brain Res 396:77-96. CrossRef Medline

Nishibe M, Urban ET 3rd, Barbay S, Nudo RJ (2015) Rehabilitative training promotes rapid motor recovery but delayed motor map reorganization in a rat cortical ischemic infarct model. Neurorehabil Neural Repair 29:472482. CrossRef Medline

Nudo RJ (2013) Recovery after brain injury: mechanisms and principles. Front Hum Neurosci 7:887. CrossRef Medline

Nudo RJ, Milliken GW (1996) Reorganization of movement representations in primary motor cortex following focal ischemic infarcts in adult squirrel monkeys. J Neurophysiol 75:2144-2149. Medline

Nudo RJ, Wise BM, SiFuentes F, Milliken GW (1996) Neural substrates for the effects of rehabilitative training on motor recovery after ischemic infarct. Science 272:1791-1794. CrossRef Medline

O'Bryant AJ, Allred RP, Maldonado MA, Cormack LK, Jones TA (2011) Breeder and batch-dependent variability in the acquisition and performance of a motor skill in adult Long-Evans rats. Behav Brain Res 224:112120. CrossRef Medline

O’Bryant AJ, Adkins DL, Sitko AA, Combs HL, Nordquist SK, Jones TA (2016) Enduring poststroke motor functional improvements by a welltimed combination of motor rehabilitative training and cortical stimulation in rats. Neurorehabil Neural Repair 30:143-154. CrossRef Medline

Overman JJ, Clarkson AN, Wanner IB, Overman WT, Eckstein I, Maguire JL, Dinov ID, Toga AW, Carmichael ST (2012) A role for ephrin-A5 in 
axonal sprouting, recovery, and activity-dependent plasticity after stroke. Proc Natl Acad Sci U S A 109:E2230-2239. CrossRef Medline

Pagnussat AS, Simao F, Anastacio JR, Mestriner RG, Michaelsen SM, Castro CC, Salbego C, Netto CA (2012) Effects of skilled and unskilled training on functional recovery and brain plasticity after focal ischemia in adult rats. Brain Res 1486:53-61. CrossRef Medline

Panatier A, Vallée J, Haber M, Murai KK, Lacaille JC, Robitaille R (2011) Astrocytes are endogenous regulators of basal transmission at central synapses. Cell 146:785-798. CrossRef Medline

Paxinos G, Watson C. The rat brain in stereotaxic coordinates. Sydney: Academic Press; 1986.

Perez-Alvarez A, Navarrete M, Covelo A, Martin ED, Araque A (2014) Structural and functional plasticity of astrocyte processes and dendritic spine interactions. J Neurosci 34:12738-12744. CrossRef Medline

Peters A, Palay SL, Webster HD (1991) The Fine Structure of the Nervous System: neurons and their supporting cells. New York: OUP.

Ramanathan D, Conner JM, Tuszynski MH (2006) A form of motor cortical plasticity that correlates with recovery of function after brain injury. Proc Natl Acad Sci U S A 103:11370-11375. CrossRef Medline

Remaud J, Ceccom J, Carponcy J, Dugué L, Menchon G, Pech S, Halley H, Francés B, Dahan L (2014) Anisomycin injection in area CA3 of the hippocampus impairs both short-term and long-term memories of contextual fear. Learn Mem 21:311-315. CrossRef Medline

Sanes JN, Donoghue JP (2000) Plasticity and primary motor cortex. Annu Rev Neurosci 23:393-415. CrossRef Medline

Sawaki L, Butler AJ, Leng X, Wassenaar PA, Mohammad YM, Blanton S, Sathian K, Nichols-Larsen DS, Wolf SL, Good DC, Wittenberg GF (2008) Constraint-induced movement therapy results in increased motor map area in subjects 3 to 9 months after stroke. Neurorehabil Neural Repair 22:505-513. CrossRef Medline

Schubring-Giese M, Leemburg S, Luft AR, Hosp JA (2016) Protein synthesis inhibition in the peri-infarct cortex slows motor recovery in rats. PLoS One 11:e0157859. CrossRef Medline

Sharma AV, Nargang FE, Dickson CT (2012) Neurosilence: profound suppression of neural activity following intracerebral administration of the protein synthesis inhibitor anisomycin. J Neurosci 32:2377-2387. CrossRef Medline

Smith JB, Alloway KD (2013) Rat whisker motor cortex is subdivided into sensory-input and motor-output areas. Front Neural Circuits 7:4. CrossRef Medline

Starkey ML, Schwab ME (2014) How plastic is the brain after a stroke? Neuroscientist 20:359-371. CrossRef Medline

Starkey ML, Bleul C, Zörner B, Lindau NT, Mueggler T, Rudin M, Schwab ME (2012) Back seat driving: hindlimb corticospinal neurons assume forelimb control following ischaemic stroke. Brain 135:3265-3281. CrossRef Medline

Sterio DC (1984) The unbiased estimation of number and sizes of arbitrary particles using the dissector. J Microsc 134:127-136. CrossRef
Sutton MA, Schuman EM (2006) Dendritic protein synthesis, synaptic plasticity, and memory. Cell 127:49-58. CrossRef Medline

Tennant KA, Adkins DL, Donlan NA, Asay AL, Thomas N, Kleim JA, Jones TA (2011) The organization of the forelimb representation of the C57BL/6 mouse motor cortex as defined by intracortical microstimulation and cytoarchitecture. Cereb Cortex 21:865-876. CrossRef Medline

Tennant KA, Kerr AL, Adkins DL, Donlan N, Thomas N, Kleim JA, Jones TA (2015) Age-dependent reorganization of peri-infarct "premotor" cortex with task-specific rehabilitative training in mice. Neurorehabil Neural Repair 29:193-202. CrossRef Medline

Veerbeek JM, van Wegen E, van Peppen R, van der Wees PJ, Hendriks E, Rietberg M, Kwakkel G (2014) What is the evidence for physical therapy poststroke? A systematic review and meta-analysis. PLoS One 9:e87987. CrossRef Medline

Wahl AS, Omlor W, Rubio JC, Chen JL, Zheng H, Schröter A, Gullo M, Weinmann O, Kobayashi K, Helmchen F, Ommer B, Schwab ME (2014) Neuronal repair. Asynchronous therapy restores motor control by rewiring of the rat corticospinal tract after stroke. Science 344:1250-1255. CrossRef Medline

Wang L, Conner JM, Nagahara AH, Tuszynski MH (2016) Rehabilitation drives enhancement of neuronal structure in functionally relevant neuronal subsets. Proc Natl Acad Sci U S A 113:2750-2755. CrossRef Medline

Wanisch K, Wotjak CT (2008) Time course and efficiency of protein synthesis inhibition following intracerebral and systemic anisomycin treatment. Neurobiol Learn Mem 90:485-494. CrossRef Medline

West MJ, Gundersen HJ (1990) Unbiased stereological estimation of the number of neurons in the human hippocampus. J Comp Neurol 296:122. CrossRef Medline

Whishaw IQ (2000) Loss of the innate cortical engram for action patterns used in skilled reaching and the development of behavioral compensation following motor cortex lesions in the rat. Neuropharmacology 39:788 805. CrossRef Medline

Whishaw IQ, Pellis SM, Gorny BP, Pellis VC (1991) The impairments in reaching and the movements of compensation in rats with motor cortex lesions: an endpoint, videorecording, and movement notation analysis. Behav Brain Res 42:77-91. CrossRef Medline

Whishaw IQ, Pellis SM, Gorny B, Kolb B, Tetzlaff W (1993) Proximal and distal impairments in rat forelimb use in reaching follow unilateral pyramidal tract lesions. Behav Brain Res 56:59-76. CrossRef Medline

Xu T, Yu X, Perlik AJ, Tobin WF, Zweig JA, Tennant K, Jones T, Zuo Y (2009) Rapid formation and selective stabilization of synapses for enduring motor memories. Nature 462:915-919. CrossRef Medline

Yu X, Wang G, Gilmore A, Yee AX, Li X, Xu T, Smith SJ, Chen L, Zuo Y (2013) Accelerated experience-dependent pruning of cortical synapses in ephrin-A2 knockout mice. Neuron 80:64-71. CrossRef Medline

Zeiler SR, Krakauer JW (2013) The interaction between training and plasticity in the poststroke brain. Curr Opin Neurol 26:609-616. CrossRef Medline 